\title{
DISRUPTING FEMALE FLIGHT IN THE VECTOR AEDES AEGYPTI
}

\author{
A Thesis \\ by \\ SARAH J. O'LEARY
Submitted to the Office of Graduate and Professional Studies of Texas A\&M University in partial fulfillment of the requirements for the degree of
MASTER OF SCIENCE

$\begin{array}{ll}\text { Chair of Committee, } & \text { Zach N. Adelman } \\ \text { Committee Members, } & \text { Kevin M. Myles } \\ & \text { Heath Blackmon } \\ & \text { Sarah H. White-Springer } \\ \text { Head of Department, } & \text { David W. Threadgill }\end{array}$

May 2021

Major Subject: Genetics

Copyright 2021 Sarah O’Leary 


\begin{abstract}
Aedes aegypti is a vector of dengue, chikungunya, and Zika viruses. Current vector control strategies such as community engagement, source reduction, and insecticides have not been sufficient to prevent viral outbreaks. Thus, interest in novel strategies involving genetic engineering is growing. Female mosquitoes rely on flight to mate with males and obtain a bloodmeal from a host. We hypothesized that knockout of genes specifically expressed in female mosquitoes associated with the indirect flight muscles would result in a flightless female mosquito. Using CRISPR-Cas9 we generated loss-of-function mutations in several genes hypothesized to control flight in mosquitoes, including actin (AeAct-4) and myosin (myo-fem) genes expressed specifically in the female flight muscle. Genetic knockout of these genes resulted in $100 \%$ flightless females, with homozygous males able to fly, mate, and produce offspring, albeit at a reduced rate when compared to wild type males. Interestingly, we found that while AeAct-4 was haplosufficient, with most heterozygous individuals capable of flight, this was not the case for myo-fem, where about half of individuals carrying only one intact copy could not fly. These findings lay the groundwork for developing novel mechanisms of controlling Ae. aegypti populations, and our results suggest that this mechanism could be applicable to other vector species of mosquito.
\end{abstract}




\section{DEDICATION}

Dedicated to my mom, my dad, my husband, and my three older sisters. For always supporting me, my education, and the decisions I have made and continue to make in life.

In memory of my sister, Becky. "If ever there's a tomorrow when we're not together... there is something you must always remember. You are braver than you believe, stronger than you seem, and smarter than you think. But the most important thing is, even if we're apart... I'll always be with you." 


\section{ACKNOWLEDGEMENTS}

Thank you to my advisor, Dr. Adelman, for taking me on as a graduate student and allowing me the opportunity to learn and grow in the research field, and in addition, for being understanding and providing guidance through difficult times and difficult decisions in my graduate student career. Also, thank you to my committee members Dr. Myles, Dr. Blackmon, and Dr. White-Springer, for facilitating my growth and aiding me in progressing through my experience in graduate school.

To all of the current and past members of our laboratory: to Drs. Bianca Kojin, Hitoshi Tsujimoto, Keun Che, and Sher Khan, for their research expertise and guidance, as well as motivation when it was very much needed; to Dr. Justin Overcash, for being a mentor, co-worker, and close friend from beginning to end; to Drs. Heather Eggelston, and Shavonn Whitten, for giving me advice and helping me through the start of graduate school; to current graduate students Alexius, Micaela, and Joe, for joining me during the graduate school journey and allowing me the opportunity to mentor you where I could; to Emma Jakes, Collin Valentin, Kristen Gilbert, Chanell Dawson, and our various undergraduates over time, for always being available to help me with any task, small or large; and to Benjamin and Sydney, for enabling me to learn how to be a mentor and teacher.

To my previous undergraduate research mentor, Dr. Troy A. Roepke, for facilitating my transition from medicine to research, helping me through the application 
process of graduate school, and always providing an accepting and caring environment to work and volunteer my time in.

To my friends, near and far; particularly Tyler Pohlenz and Elizabeth (Dr. Liz!) Walsh, for thoughtful conversations, guidance, and advice even I sometimes did not want to (but needed to) hear. Also, for having awesome pets.

Lastly, thank you to my family; my husband, my parents, and my sisters, for everything. 


\section{CONTRIBUTORS AND FUNDING SOURCES}

\section{Contributors}

This research was supervised by a thesis committee consisting of Dr. Zach N. Adelman [advisor] of the Department of Entomology, Dr. Kevin M. Myles of the Department of Entomology, Dr. Heath Blackmon of the Department of Biology, and Dr. Sarah H. White-Springer of the Department of Animal Science.

All work for Chapter 2 was completed by the student, under the advisement of Dr. Zach N. Adelman, and was published in December 2020.

\section{Funding Sources}

This research was supported by Texas A\&M Agrilife Research (Insect Vectored Disease Grant Program) to ZNA and the Genetics Program (SO) at Texas A\&M University. Its contents are solely the responsibility of the authors and do not necessarily represent the official views of Texas A\&M University. 


\section{TABLE OF CONTENTS}

Page

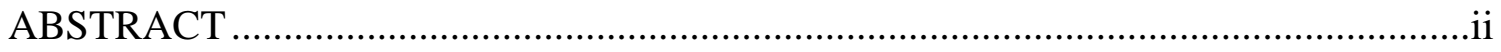

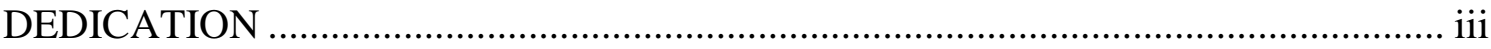

ACKNOWLEDGEMENTS …………………………..........................................

CONTRIBUTORS AND FUNDING SOURCES.........................................................vi

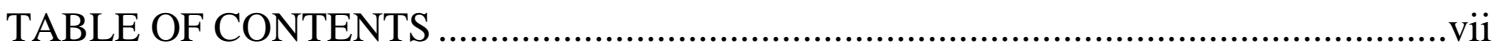

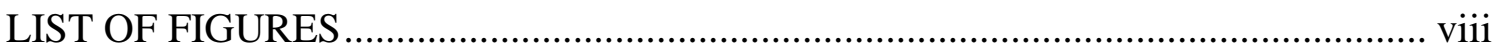

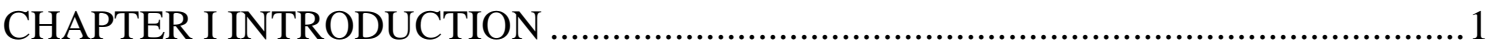

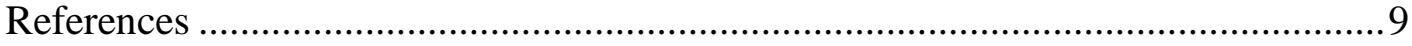

CHAPTER II CRISPR/CAS9 KNOCKOUT OF FEMALE-BIASED GENES

AEACT-4 OR MYO-FEM IN AE. AEGYPTI RESULTS IN A FLIGHTLESS

PHENOTYPE IN FEMALE, BUT NOT MALE MOSQUITOES .................................20

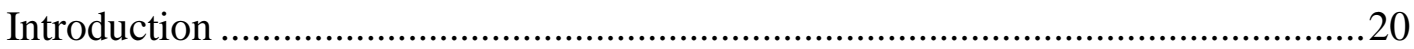

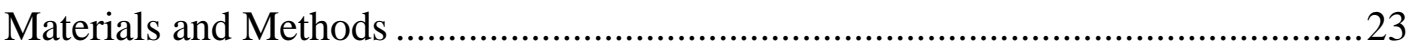

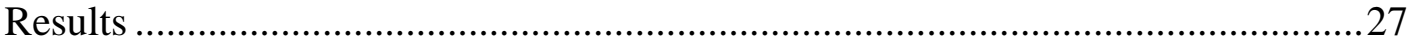

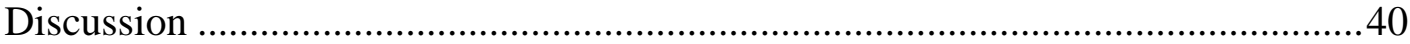

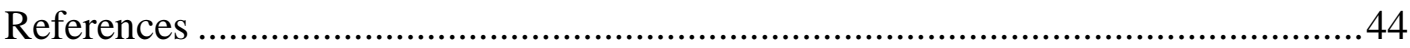

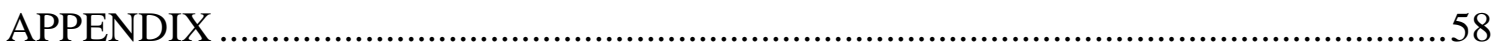

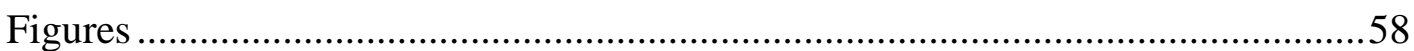

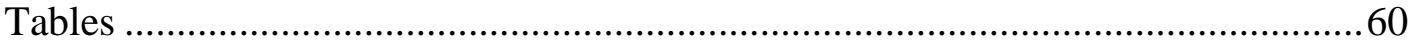

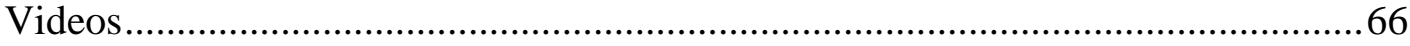

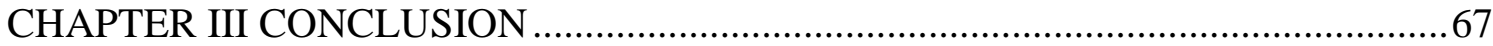

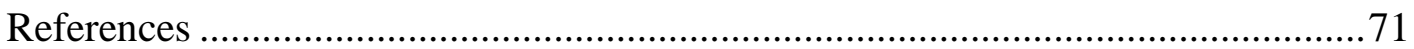

vii 


\section{LIST OF FIGURES}

Page

Fig 1. Development of CRISPR reagents targeting Ae. aegypti genes involved in flight.

Fig 2. Establishment and maintenance of heritable loss-of-function mutations in $A e$.

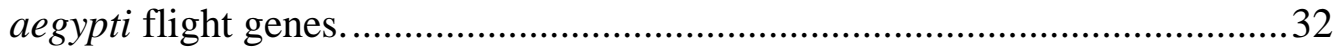

Fig 3. Loss of AeAct-4, myo-fem, or Aeflightin results in flightlessness..........................34

Fig 4. Mating competitiveness of male Ae. aegypti deficient in AeAct-4 or myo-fem.....37

Fig 5. Neighbor-joining tree of AeAct-4 and related homologs in mosquitoes................39

Fig 6. An M-locus-linked sex distorter gene drive targeting female-specific flight genes. 


\section{CHAPTER I}

\section{INTRODUCTION}

The yellow fever mosquito Aedes aegypti is a vector for many viruses of medical significance. It originated from Africa, but can now be found in tropical, subtropical, and temperate regions of the world [1]. Spread of Ae. aegypti can be attributed to the development of global trade and shipments [2]. The use of this species in a laboratory setting is ideal because they are easily reared, their eggs can be dried and stored for a few months [3], and they have a rapid life cycle. The life cycle includes four stages: egg, larval, pupal, and adult. The eggs, once fully developed, will hatch when covered with water, and the larvae will progress through four instars until they reach the pupal stage. Both the larval and pupal stages are aquatic. Once the adult mosquito emerges from the pupal casing, it can fly away [4]. The majority of males will develop to the pupal stage before females, a term referred to as protandry [5]. The females are the ones who blood feed and ultimately transmit viruses. Ae. aegypti are anthropophilic, meaning they prefer biting humans, and are also day biters (predominantly at dusk and dawn). Once a blood meal is obtained, a female can successfully produce eggs, as the blood is required for her egg production. After mating, a single female can lay about 100 eggs at a time, up to five times. The overall lifespan of an adult Ae. aegypti mosquito is 2-4 weeks [2].

A draft genome of Ae. aegypti (the Liverpool strain) was sequenced and published in 2007. This assembly was highly fragmented, due to the Sanger sequencing method being unable to span long transposable elements [6], which make up $47 \%$ of the 
genome [7]. With the identification of new genes, a developmental and neurotranscriptome [8, 9], physical mapping of chromosomes [10, 11], and Hi-C assembly methods [12], the genome was resequenced using PacBio technology and assembled in 2017 [13]. The revised genome consists of three chromosomes, one of which is a homomorphic sex determining chromosome encoding the $\mathrm{M}$ factor (nix), the gene that determines maleness in Ae. aegypti [14].

Aedes aegypti is a vector for viruses such as dengue, chikungunya, yellow fever, and Zika. After taking an initial blood meal from an infected individual, the virus replicates within the mosquito and ultimately ends up in the salivary glands. When a second blood meal is taken from an uninfected individual, the mosquito transmits the virus in the saliva during the bloodfeeding process. Outbreaks of dengue have been reported in Texas in 2005, Florida from 2009 to 2011 [1], and Hawaii in 2015 [15]. Chikungunya virus has been reported before in Florida and Texas [1], and yellow fever virus has historically been seen in New York, Pennsylvania, and Massachusetts, but it has not been reported since 1905 [16]. Zika virus also reached the United States in 2016 [1]. A vaccine for yellow fever is available [17], but for the other viruses, either no vaccine is available, or in the case of dengue virus, it is a limited vaccine based on age and previous infection status [15]. Even in the case that yellow fever vaccines are available, there is issues with poor distribution [3]. With no effective vaccines for certain viruses, and only being able to treat the symptoms of the disease, current vector control strategies focus on prevention of the spread of viruses by Ae. aegypti. 
Current strategies for vector control include mosquito-based surveillance, community education, source reduction, and chemical methods. Surveillance of mosquitoes will help determine the presence or abundance of species in specific areas, as well as the risk to humans. Ovitraps, adult traps, and aquatic stage collection is used for this method, which is more helpful for measuring the effectiveness of other control strategies. Community education includes door-to-door campaigns and distribution of surveys to inform individuals in the community on how to prevent mosquito bites [18]. Within community education is source reduction, because removal of mosquito breeding habitats can involve personal property, which can only be performed by individuals in the community who are informed. Source reduction or environmental management can include removal of stagnant water (found in items such as disposable containers, potted plants, toys, etc.), screening of windows and doors, and personal protection (or covering of skin) [2]. Chemical methods, such as insecticides or larvicides, can be on an individual level, or as large as ground and aerial spraying [18].

Despite implementing the current vector control strategies mentioned above, there are issues associated with them. Re-establishment can occur if eradication programs are not maintained [2]. The issues regarding community commitment include a lack of support for vector control programs, and a need for trained staff [3]. Some of the vector control strategies are short term, and the financial maintenance of them can be costly. Lastly, with the use of chemical methods (like insecticides), concerns of resistance arise, as well as exposure to individuals and off-target species being affected [3]. All these issues support a need for novel vector control strategies. 
Genetic control strategies include sterile insect technique (SIT) [19-24], release of an insect carrying a dominant lethal (RIDL) [5, 19, 23], and gene drive [25-34]. Traditional SIT involves irradiation of mosquitoes, producing sterile males, which are sex-sorted for male-only release into the environment. The goal of traditional SIT is to prevent wild female mosquitoes from being able to produce viable progeny by mating with the sterile males, leading to a population decline or collapse. This method has the potential to be environmentally friendly and species-specific. However, it can be difficult to irradiate mass quantities of mosquitoes, not every mosquito species can be sex-sorted, male-only release is crucial (to prevent female release which would contribute towards bloodfeeding behaviors), and the sterile males may suffer other fitness effects from the irradiation [19-21]. The development of genetic sexing strains is being explored to help ease the sex-sorting and male-only release portion of SIT [5]. RIDL is a modified version of SIT. RIDL utilizes a heritable, lethal gene that would be expressed later in development, removing individuals from a population before they reach the adult stage. This enables competition throughout the other developmental stages and removes the need for irradiation. RIDL has been used previously in the Cayman Islands, Malaysia, and Brazil [19].

Gene drive is the spread of a genetic element beyond Mendelian rates of inheritance [25, 34-36]. It has been proposed to be used to accomplish vector population replacement [27-30], suppression [26, 31-33], or elimination [37]. Some examples of natural gene drive systems include transposons (such as P elements in Drosophila), Medea (maternal-effect dominant embryonic arrest, or toxin-antidote systems), homing 
endonucleases, and symbionts (such as Wolbachia) [19, 34, 37]. Synthetic gene drives can take advantage of the CRISPR/Cas9 system to target a specific location in the genome to catalyze a double-stranded break (reviewed in [25]). Homology directed repair (HDR) is one DNA repair pathway that, when coupled with CRISPR/Cas9 gene drive systems, contributes towards the hyper-Mendelian rates of inheritance of the gene drive. HDR uses a homologous chromosome or sequence to repair the double-stranded break in the DNA. If the homologous sequence used for repair contains the transgene(s), then the Cas9 nuclease and any associated transgenes will increase in frequency after HDR occurs. The error-prone DNA repair pathway, non-homologous end joining (NHEJ), has been shown to increase the potential of resistant alleles for gene drives [31, $32,38]$, due to the occurrence of mutations at the target site of the gene drive after NHEJ occurs. Multiplexing of guide RNAs has been shown to increase gene drive efficiency, while decreasing the probability of resistance to the gene drive $[33,39,40]$. Despite the increasing popularity of these alternative strategies, there are regulatory rules and political issues that need to be considered, as well as community awareness $[19,20]$ before environmental releases could occur.

The CRISPR (clustered regularly interspaced palindromic repeats) system is an adaptive immune response that has evolved in bacteria and archaea. Since it has been discovered and the components of the system further understood, it has become an easy, efficient, inexpensive method for editing genomes [41]. The associated Cas protein is an RNA-guided DNA endonuclease, which induces a double-stranded break in the DNA. The synthetic guide RNA has a 20 nucleotide DNA binding region that can be selected 
for based on a specific region in the genome, with a 3 nucleotide protospacer adjacent motif (PAM) region that is also required for inducing the double-stranded break [42]. After the double-stranded break occurs, DNA repair mechanisms such as nonhomologous end joining, or homology directed repair, can take place. These two DNA repair mechanisms can be used to disrupt a gene (by formation of insertions or deletions, "indels") or insert a construct at a specific location. The CRISPR/Cas9 system has been utilized in Aedes aegypti as an effective tool for genome editing [43-47] and gene drive [47]. Other considerations like off-target effects and resistant alleles are still of concern and should be considered when using this method.

To be able to target a species for population control or elimination, an understanding of the species life cycle, up-to-date genome information, and efficient genome editing techniques are needed. Optimal promoters or genes to use as a target in a mosquito would be during late stages in development, such as the pupal stage, before the mosquito reaches adulthood, and in a critical tissue or organ that greatly contributes towards survival. They should also be sex-specific, and in the case of Aedes aegypti, female-specific, as females are the ones who bite to obtain a blood meal. If the gene is well conserved, that also helps decrease the chance of off-target effects when selecting guide RNAs to use with the CRISPR/Cas9 system.

Based on publicly available RNA-seq data from Akbari et al. (2013), there are certain genes expressed in Ae. aegypti which are sex-specific, and other genes that are expressed during the pupal stage $[14,48-50]$. Flight muscle associated genes could potentially fit both categories. If flight in female mosquitoes can be disrupted, then the 
resulting females would be prevented from mating or obtaining the blood meal required to produce eggs. In fact, flightless mosquitoes likely could not escape from their aquatic habitat after emerging from the pupal casing, making the flight muscles a critical tissue for the mosquito [51]. In muscles, actin and myosin are the main proteins involved in contractions. The muscle fibers contain thin actin filaments and thick myosin filaments, which slide across each other to perform the "power stroke", or sliding filament theory of contraction [52]. Any disruption of these muscle proteins will lead to a decreased protein function or elimination of the ability to perform muscle contractions.

AeAct-4 was identified to be female- and pupal-specific, expressed in the longitudinal and dorsoventral indirect flight muscles of Ae. aegypti [49]. Although there is evidence of low levels of transcription in males, the promoter has been used in transgenic strains to express an intracellular toxin that resulted in a female-specific flightless phenotype [51], with laboratory cage trials [53] and field cage trials being performed. Population elimination was observed in laboratory cage trials, however in field cage trials, only population suppression was observed, due to decreased mating competitiveness of homozygous transgenic males [54]. Previously, Aeact-1 [55], AeAct2, and AeAct-3 (male-specific) [50] have been identified as muscle actins, and AeAct-4 has $\sim 60 \%$ nucleotide similarity to other Aedes aegypti actins, with $\sim 95 \%$ amino acid similarity to other insect actins [49], making it an ideal, conserved gene to target for population control. Like with actin, there are male- and female-specific myosin muscle genes in Ae. aegypti. The male-specific myo-sex was identified and found to be linked to the M-locus on chromosome one, with an autosomal paralog (female-specific) identified 
on chromosome two [48]. Knockout of the male-specific myosin gene has shown that it is needed for male flight [56].

In Drosophila melanogaster, another stage-specific gene, flightin, was identified to produce a protein in the indirect flight muscles. This protein was found to interact with myosin, so it is similarly compared to actin, with the amino terminus showing sequence similarity between the two [57]. There is an orthologue to flightin in Ae. aegypti, although it is not sex specific. Despite this lack of specificity in females, flightin can still be explored as an option to target flight in females, so long as a male-specific rescue can be performed.

The current control methods to prevent the spread of Aedes aegypti have limitations and should be used in combination with genetic control strategies. With advances in gene editing technology and the availability of the genome of Ae. aegypti, our goal was to identify and target flight genes that exhibited female-specific and/or pupal-specific expression for knockout utilizing CRISPR/Cas9 technology. We hypothesized that knockout of these critical muscle flight genes would result in flightlessness. For the genes specific to females, we also hypothesized that flight in males would not be affected. The findings in this thesis lay the groundwork for future development of novel genetic control strategies for Ae. aegypti. 


\section{References}

1. CDC. Surveillance and Control of Aedes aegypti and Aedes albopictus in the United States. 2017.

2. Zettel C, Kaufman P. Yellow fever mosquito Aedes aegypti (Linnaeus) (Insecta: Diptera: Culicidae). Featured Creatures [Internet]. 2009:[8 p.].

3. Clemons A, Haugen M, Flannery E, Tomchaney M, Kast K, Jacowski C, et al. Aedes aegypti: an emerging model for vector mosquito development. Cold Spring Harb Protoc. 2010;2010(10):pdb emo141. Epub 2010/10/05. doi: 10.1101/pdb.emo141. PubMed PMID: 20889691; PubMed Central PMCID: PMCPMC2975269.

4. $\quad$ CDC. Mosquito life cycle. 2018.

5. Gilles JR, Schetelig MF, Scolari F, Marec F, Capurro ML, Franz G, et al. Towards mosquito sterile insect technique programmes: exploring genetic, molecular, mechanical and behavioural methods of sex separation in mosquitoes. Acta Trop. 2014;132 Suppl:S178-87. Epub 2013/09/03. doi: 10.1016/j.actatropica.2013.08.015. PubMed PMID: 23994521.

6. Turner J, Krishna R, Van't Hof AE, Sutton ER, Matzen K, Darby AC. The sequence of a male-specific genome region containing the sex determination switch in Aedes aegypti. Parasit Vectors. 2018;11(1):549. Epub 2018/10/22. doi: 10.1186/s13071018-3090-3. PubMed PMID: 30342535; PubMed Central PMCID: PMCPMC6195999. 7. Nene V, Wortman JR, Lawson D, Haas B, Kodira C, Tu ZJ, et al. Genome sequence of Aedes aegypti, a major arbovirus vector. Science. 2007;316(5832):1718-23. 
Epub 2007/05/19. doi: 10.1126/science.1138878. PubMed PMID: 17510324; PubMed Central PMCID: PMCPMC2868357.

8. Akbari OS, Antoshechkin I, Amrhein H, Williams B, Diloreto R, Sandler J, et al. The developmental transcriptome of the mosquito Aedes aegypti, an invasive species and major arbovirus vector. G3 (Bethesda). 2013;3(9):1493-509. Epub 2013/07/09. doi: 10.1534/g3.113.006742. PubMed PMID: 23833213; PubMed Central PMCID: PMCPMC3755910.

9. Matthews BJ, McBride CS, DeGennaro M, Despo O, Vosshall LB. The neurotranscriptome of the Aedes aegypti mosquito. BMC Genomics. 2016;17:32. Epub 2016/01/08. doi: 10.1186/s12864-015-2239-0. PubMed PMID: 26738925; PubMed Central PMCID: PMCPMC4704297.

10. Timoshevskiy VA, Kinney NA, deBruyn BS, Mao C, Tu Z, Severson DW, et al. Genomic composition and evolution of Aedes aegypti chromosomes revealed by the analysis of physically mapped supercontigs. BMC Biol. 2014;12:27. Epub 2014/04/16. doi: 10.1186/1741-7007-12-27. PubMed PMID: 24731704; PubMed Central PMCID: PMCPMC4021624.

11. Timoshevskiy VA, Severson DW, Debruyn BS, Black WC, Sharakhov IV, Sharakhova MV. An integrated linkage, chromosome, and genome map for the yellow fever mosquito Aedes aegypti. PLoS neglected tropical diseases. 2013;7(2):e2052. Epub 2013/03/06. doi: 10.1371/journal.pntd.0002052. PubMed PMID: 23459230; PubMed Central PMCID: PMCPMC3573077. 
12. Dudchenko O, Batra SS, Omer AD, Nyquist SK, Hoeger M, Durand NC, et al. De novo assembly of the Aedes aegypti genome using Hi-C yields chromosome-length scaffolds. Science. 2017;356(6333):92-5. Epub 2017/03/25. doi:

10.1126/science.aal3327. PubMed PMID: 28336562; PubMed Central PMCID: PMCPMC5635820.

13. Matthews BJ, Dudchenko O, Kingan SB, Koren S, Antoshechkin I, Crawford JE, et al. Improved reference genome of Aedes aegypti informs arbovirus vector control. Nature. 2018;563(7732):501-7. Epub 2018/11/16. doi: 10.1038/s41586-018-0692-Z. PubMed PMID: 30429615; PubMed Central PMCID: PMCPMC6421076.

14. Hall AB, Basu S, Jiang X, Qi Y, Timoshevskiy VA, Biedler JK, et al. SEX DETERMINATION. A male-determining factor in the mosquito Aedes aegypti. Science. 2015;348(6240):1268-70. Epub 2015/05/23. doi: 10.1126/science.aaa2850. PubMed PMID: 25999371; PubMed Central PMCID: PMCPMC5026532.

15. WHO. Dengue and severe dengue 2019 [updated April 15, 2019June 24, 2019]. Available from: https://www.who.int/news-room/fact-sheets/detail/dengue-and-severe-

\section{dengue.}

16. Eisen L, Moore CG. Aedes (Stegomyia) aegypti in the Continental United States: A Vector at the Cool Margin of Its Geographic Range. Journal of Medical Entomology. 2013;50(3):467-78. doi: 10.1603/ME12245.

17. Thieler M, Smith, H. H. The effect of prolonged cultivation in vitro upon the pathogenicity of yellow fever virus. J Exp Med. 1937;65:767-86. 
18. CDC. Help Control Mosquitoes that Spread Dengue, Chikungunya, and Zika Viruses. 2015.

19. Alphey L. Genetic control of mosquitoes. Annu Rev Entomol. 2014;59:205-24. Epub 2013/10/29. doi: 10.1146/annurev-ento-011613-162002. PubMed PMID: 24160434 .

20. Alphey L, Nimmo D, O'Connell S, Alphey N. Insect Population Suppression Using Engineered Insects. New York, New York: Landes Bioscience and Spring Science+Business Media; 2008.

21. Bond JG, Osorio AR, Avila N, Gomez-Simuta Y, Marina CF, Fernandez-Salas I, et al. Optimization of irradiation dose to Aedes aegypti and Ae. albopictus in a sterile insect technique program. PLoS One. 2019;14(2):e0212520. Epub 2019/02/20. doi:

10.1371/journal.pone.0212520. PubMed PMID: 30779779; PubMed Central PMCID: PMCPMC6380561.

22. Kandul NP, Liu J, Sanchez CH, Wu SL, Marshall JM, Akbari OS. Transforming insect population control with precision guided sterile males with demonstration in flies. Nat Commun. 2019;10(1):84. Epub 2019/01/10. doi: 10.1038/s41467-018-07964-7. PubMed PMID: 30622266; PubMed Central PMCID: PMCPMC6325135.

23. McGraw EA, O'Neill SL. Beyond insecticides: new thinking on an ancient problem. Nat Rev Microbiol. 2013;11(3):181-93. Epub 2013/02/16. doi: 10.1038/nrmicro2968. PubMed PMID: 23411863. 
24. Zheng X, Zhang D, Li Y, Yang C, Wu Y, Liang X, et al. Incompatible and sterile insect techniques combined eliminate mosquitoes. Nature. 2019;572(7767):56-61. Epub 2019/07/19. doi: 10.1038/s41586-019-1407-9. PubMed PMID: 31316207.

25. Akbari OS, Bellen HJ, Bier E, Bullock SL, Burt A, Church GM, et al. BIOSAFETY. Safeguarding gene drive experiments in the laboratory. Science. 2015;349(6251):927-9. Epub 2015/08/01. doi: 10.1126/science.aac7932. PubMed PMID: 26229113; PubMed Central PMCID: PMCPMC4692367.

26. Akbari OS, Matzen KD, Marshall JM, Huang H, Ward CM, Hay BA. A synthetic gene drive system for local, reversible modification and suppression of insect populations. Curr Biol. 2013;23(8):671-7. Epub 2013/04/02. doi:

10.1016/j.cub.2013.02.059. PubMed PMID: 23541732.

27. Buchman A, Gamez S, Li M, Antoshechkin I, Li HH, Wang HW, et al. Broad dengue neutralization in mosquitoes expressing an engineered antibody. PLoS Pathog. 2020;16(1):e1008103. Epub 2020/01/17. doi: 10.1371/journal.ppat.1008103. PubMed PMID: 31945137; PubMed Central PMCID: PMCPMC6964813 J.E.C. has served as a consultant for Takeda Vaccines, Sanofi Pasteur, Pfizer, and Novavax, is on the Scientific Advisory Boards of CompuVax, GigaGen, Meissa Vaccines, and is the Founder of IDBiologics, Inc. All other authors declare no competing financial interests.

28. Buchman A, Gamez S, Li M, Antoshechkin I, Li HH, Wang HW, et al. Engineered resistance to Zika virus in transgenic Aedes aegypti expressing a polycistronic cluster of synthetic small RNAs. Proceedings of the National Academy of Sciences of the United States of America. 2019;116(9):3656-61. Epub 2019/02/07. doi: 
10.1073/pnas.1810771116. PubMed PMID: 30723148; PubMed Central PMCID: PMCPMC6397566.

29. Buchman AB, Ivy T, Marshall JM, Akbari OS, Hay BA. Engineered Reciprocal Chromosome Translocations Drive High Threshold, Reversible Population Replacement in Drosophila. ACS Synth Biol. 2018;7(5):1359-70. Epub 2018/04/03. doi:

10.1021/acssynbio.7b00451. PubMed PMID: 29608276.

30. Gantz VM, Jasinskiene N, Tatarenkova O, Fazekas A, Macias VM, Bier E, et al. Highly efficient Cas9-mediated gene drive for population modification of the malaria vector mosquito Anopheles stephensi. Proceedings of the National Academy of Sciences of the United States of America. 2015;112(49):E6736-43. Epub 2015/11/26. doi: 10.1073/pnas.1521077112. PubMed PMID: 26598698; PubMed Central PMCID: PMCPMC4679060.

31. Hammond AM, Kyrou K, Gribble M, Karlsson X, Morianou I, Galizi R, et al. Improved CRISPR-based suppression gene drives mitigate resistance and impose a large reproductive load on laboratory-contained mosquito populations. bioRxiv. 2018. doi: $10.1101 / 360339$.

32. KaramiNejadRanjbar M, Eckermann KN, Ahmed HMM, Sanchez CH, Dippel S, Marshall JM, et al. Consequences of resistance evolution in a Cas9-based sex conversion-suppression gene drive for insect pest management. Proceedings of the National Academy of Sciences of the United States of America. 2018;115(24):6189-94. Epub 2018/05/31. doi: 10.1073/pnas.1713825115. PubMed PMID: 29844184; PubMed Central PMCID: PMCPMC6004448. 
33. Oberhofer G, Ivy T, Hay BA. Behavior of homing endonuclease gene drives targeting genes required for viability or female fertility with multiplexed guide RNAs. Proceedings of the National Academy of Sciences of the United States of America. 2018;115(40):E9343-E52. Epub 2018/09/19. doi: 10.1073/pnas.1805278115. PubMed PMID: 30224454; PubMed Central PMCID: PMCPMC6176634.

34. Sinkins SP, Gould F. Gene drive systems for insect disease vectors. Nat Rev Genet. 2006;7(6):427-35. Epub 2006/05/10. doi: 10.1038/nrg 1870. PubMed PMID: 16682981.

35. Noble C, Min J, Olejarz J, Buchthal J, Chavez A, Smidler AL, et al. Daisy-chain gene drives for the alteration of local populations. Proceedings of the National Academy of Sciences of the United States of America. 2019;116(17):8275-82. Epub 2019/04/04. doi: 10.1073/pnas.1716358116. PubMed PMID: 30940750; PubMed Central PMCID: PMCPMC6486765.

36. Oberhofer G, Ivy T, Hay BA. Cleave and Rescue, a novel selfish genetic element and general strategy for gene drive. Proceedings of the National Academy of Sciences of the United States of America. 2019;116(13):6250-9. Epub 2019/02/15. doi:

10.1073/pnas.1816928116. PubMed PMID: 30760597; PubMed Central PMCID: PMCPMC6442612.

37. Terenius O, Marinotti O, Sieglaff D, James AA. Molecular genetic manipulation of vector mosquitoes. Cell Host Microbe. 2008;4(5):417-23. Epub 2008/11/11. doi: 10.1016/j.chom.2008.09.002. PubMed PMID: 18996342; PubMed Central PMCID: PMCPMC2656434. 
38. Unckless RL, Clark AG, Messer PW. Evolution of Resistance Against CRISPR/Cas9 Gene Drive. Genetics. 2017;205(2):827-41. Epub 2016/12/13. doi: 10.1534/genetics.116.197285. PubMed PMID: 27941126; PubMed Central PMCID: PMCPMC5289854.

39. Champer J, Liu J, Oh SY, Reeves R, Luthra A, Oakes N, et al. Reducing resistance allele formation in CRISPR gene drive. Proceedings of the National Academy of Sciences of the United States of America. 2018;115(21):5522-7. Epub 2018/05/08. doi: 10.1073/pnas.1720354115. PubMed PMID: 29735716; PubMed Central PMCID: PMCPMC6003519.

40. Yan Y, Finnigan GC. Development of a multi-locus CRISPR gene drive system in budding yeast. Sci Rep. 2018;8(1):17277. Epub 2018/11/24. doi: 10.1038/s41598018-34909-3. PubMed PMID: 30467400; PubMed Central PMCID: PMCPMC6250742. 41. Jinek M, Chylinski K, Fonfara I, Hauer M, Doudna JA, Charpentier E. A programmable dual-RNA-guided DNA endonuclease in adaptive bacterial immunity. Science. 2012;337(6096):816-21. Epub 2012/06/30. doi: 10.1126/science.1225829. PubMed PMID: 22745249; PubMed Central PMCID: PMCPMC6286148.

42. Qi LS, Larson MH, Gilbert LA, Doudna JA, Weissman JS, Arkin AP, et al. Repurposing CRISPR as an RNA-guided platform for sequence-specific control of gene expression. Cell. 2013;152(5):1173-83. Epub 2013/03/05. doi:

10.1016/j.cell.2013.02.022. PubMed PMID: 23452860; PubMed Central PMCID: PMCPMC3664290. 
43. Basu S, Aryan A, Overcash JM, Samuel GH, Anderson MA, Dahlem TJ, et al. Silencing of end-joining repair for efficient site-specific gene insertion after TALEN/CRISPR mutagenesis in Aedes aegypti. Proceedings of the National Academy of Sciences of the United States of America. 2015;112(13):4038-43. Epub 2015/03/17. doi: 10.1073/pnas.1502370112. PubMed PMID: 25775608; PubMed Central PMCID: PMCPMC4386333.

44. Kistler KE, Vosshall LB, Matthews BJ. Genome engineering with CRISPR-Cas9 in the mosquito Aedes aegypti. Cell Rep. 2015;11(1):51-60. Epub 2015/03/31. doi: 10.1016/j.celrep.2015.03.009. PubMed PMID: 25818303; PubMed Central PMCID: PMCPMC4394034.

45. Chaverra-Rodriguez D, Macias VM, Hughes GL, Pujhari S, Suzuki Y, Peterson DR, et al. Targeted delivery of CRISPR-Cas9 ribonucleoprotein into arthropod ovaries for heritable germline gene editing. Nat Commun. 2018;9(1):3008. Epub 2018/08/03. doi: 10.1038/s41467-018-05425-9. PubMed PMID: 30068905; PubMed Central PMCID: PMCPMC6070532.

46. Li M, Bui M, Yang T, Bowman CS, White BJ, Akbari OS. Germline Cas9 expression yields highly efficient genome engineering in a major worldwide disease vector, Aedes aegypti. Proceedings of the National Academy of Sciences of the United States of America. 2017;114(49):E10540-E9. Epub 2017/11/16. doi: 10.1073/pnas.1711538114. PubMed PMID: 29138316; PubMed Central PMCID: PMCPMC5724270. 
47. Li M, Yang T, Kandul NP, Bui M, Gamez S, Raban R, et al. Development of a Confinable Gene-Drive System in the Human Disease Vector, Aedes aegypti. 2019. doi: $10.1101 / 645440$.

48. Hall AB, Timoshevskiy VA, Sharakhova MV, Jiang X, Basu S, Anderson MA, et al. Insights into the preservation of the homomorphic sex-determining chromosome of Aedes aegypti from the discovery of a male-biased gene tightly linked to the M-locus. Genome Biol Evol. 2014;6(1):179-91. Epub 2014/01/09. doi: 10.1093/gbe/evu002. PubMed PMID: 24398378; PubMed Central PMCID: PMCPMC3914700.

49. Muñoz D, Jimenez A, Marinotti O, James AA. The AeAct-4 gene is expressed in the developing flight muscles of female Aedes aegypti. Insect molecular biology. 2004;13(5):563-8.

50. Vyazunova I, Lan Q. Stage-specific expression of two actin genes in the yellow fever mosquito, Aedes aegypti. Insect molecular biology. 2004;13(5):241-9.

51. Fu G, Lees RS, Nimmo D, Aw D, Jin L, Gray P, et al. Female-specific flightless phenotype for mosquito control. Proceedings of the National Academy of Sciences of the United States of America. 2010;107(10):4550-4. Epub 2010/02/24. doi:

10.1073/pnas.1000251107. PubMed PMID: 20176967; PubMed Central PMCID: PMCPMC2826341.

52. Silverthorn DU. Human physiology: an integrated approach. Boston: Pearson; 2013.

53. Wise de Valdez MR, Nimmo D, Betz J, Gong HF, James AA, Alphey L, et al. Genetic elimination of dengue vector mosquitoes. Proceedings of the National Academy 
of Sciences of the United States of America. 2011;108(12):4772-5. Epub 2011/03/09. doi: 10.1073/pnas.1019295108. PubMed PMID: 21383140; PubMed Central PMCID: PMCPMC3064365.

54. Facchinelli L, Valerio L, Ramsey JM, Gould F, Walsh RK, Bond G, et al. Field cage studies and progressive evaluation of genetically-engineered mosquitoes. PLoS neglected tropical diseases. 2013;7(1):e2001. Epub 2013/01/26. doi:

10.1371/journal.pntd.0002001. PubMed PMID: 23350003; PubMed Central PMCID: PMCPMC3547837.

55. Ibrahim MS, Eisinger SW, Scott AL. Muscle Actin Gene from Aedes aegypti (Diptera: Culicidae). J Med Entomol. 1996;33(6):955-62.

56. Aryan A, Anderson MAE, Biedler JK, Qi Y, Overcash JM, Naumenko AN, et al. Nix alone is sufficient to convert female Aedes aegypti into fertile males and myo-sex is needed for male flight. Proceedings of the National Academy of Sciences of the United States of America. 2020;117(30):17702-9. Epub 2020/07/15. doi:

10.1073/pnas.2001132117. PubMed PMID: 32661163; PubMed Central PMCID: PMCPMC7395513.

57. Vigoreaux JO. Flightin, a novel myofibrillar protein of Drosophila stretchactivated muscles. The Journal of Cell Biology. 1993;121(3):587-98. doi:

10.1083/jcb.121.3.587. 


\section{CHAPTER II}

\section{CRISPR/CAS9 KNOCKOUT OF FEMALE-BIASED GENES AEACT-4 OR MYO-} FEM IN AE. AEGYPTI RESULTS IN A FLIGHTLESS PHENOTYPE IN FEMALE, BUT NOT MALE MOSQUITOES*

Introduction

The yellow fever mosquito Aedes aegypti is a vector for many viruses of medical significance, such as dengue, Zika, chikungunya, and yellow fever, and they can be found in tropical, subtropical, and temperate regions of the world [1]. Only female $A e$. aegypti bite to obtain a blood meal, which is required for egg production. After hatching from the embryo, Ae. aegypti like all other mosquito species will progress through the aquatic larval and pupal stages of their life, before emerging as an adult from the pupal casing to fly away [2,3].

Due to a lack of safe, effective vaccines for most viruses transmitted by Ae. aegypti, save yellow fever virus [4], control efforts largely focus on reducing vector abundance, and include source reduction, and chemical methods like insecticides or larvicides $[3,5]$. The short-term effect and high financial cost, along with the need for trained staff, presents challenges to the implementation, scaling, and maintenance of these control methods $[3,6]$. With chemical methods, additional concerns relating to the

\footnotetext{
* Reprinted with permission from "CRISPR/Cas9 knockout of female-biased genes AeAct-4 or myo-fem in Ae. aegypti results in a flightless phenotype in female, but not male mosquitoes" by O'Leary $\mathrm{S}$, Adelman ZN, 2020. PLoS Negl Trop Dis, 14(12).
} 
emergence of resistance and effects on off-target species are increasing [6]. Because of these limitations, the need for novel vector control strategies is growing.

Genetic control strategies are receiving an increased amount of attention as viable vector control approaches, and include sterile insect technique (SIT) [7-12], release of an insect carrying a dominant lethal (RIDL) $[7,10,13]$, and potentially gene drive [14-23]. Gene drive involves the spread of a genetic element beyond Mendelian rates of inheritance [14,23-25]. Synthetic gene drive mechanisms can take advantage of the CRISPR/Cas9 system, which allows targeting of the genome at a precise location to catalyze a double-stranded break with repair outcomes (non-homologous end joining or homology directed repair) determining whether the result is targeted disruption or copying of a cargo sequence. Population suppression approaches to vector control with genetic modifications seek to, in some way, prevent the female mosquito from being able to bloodfeed or mate, thus producing fewer or no offspring and leading to a population decline or collapse [15,20-22]. Population replacement can couple a cargo, such as refractoriness to a pathogen, with a gene drive to potentially replace the native vector population with a new population less capable of transmitting the pathogen [1619]. Much work is being put in to understanding the formation of alleles resistant to CRISPR/Cas9 cleavage $[20,21,26-29]$ and to increasing gene drive efficiencies overall [22,27,28,30-32]. Meanwhile, the CRISPR/Cas9 system has now become an efficient and inexpensive method for genome editing [33], and it has been utilized effectively in Ae. aegypti for both genome editing [34-38] and gene drive [38]. 
A function that is critical for both reproduction and survival in female mosquitoes is flight, as flight is required for mating, obtaining a blood meal, and escaping from aquatic breeding sites after eclosion. AeAct-4 was identified previously as a female- and pupal-specific gene, with expression in the indirect flight muscles [39]. Other work in Ae. aegypti has identified a male-specific actin gene [40] and malespecific myosin gene [41] related to flight, while in Drosophila melanogaster, Flightin has been identified as a flight-associated protein that is hypothesized to function in the indirect flight muscles of both sexes by interacting with myosin filaments or by modulating actin-myosin interactions [42]. Knockout of the male-specific myosin gene has shown that it is needed for male flight [43], and offers up the possibility that male and female flight in Aedes mosquitoes is controlled separately by these sex-specific genes.

To determine the importance of selected actin and myosin genes to Ae. aegypti female flight, we used CRISPR/Cas9 to generate heritable loss-of-function alleles in AeAct-4 and a female-biased myosin gene which we termed myo-fem, along with a third gene, Aeflightin, that is expressed in both males and females. Phenotypic analysis of individuals homozygous for each introduced mutation in AeAct-4 or myo-fem confirmed that flight defects were both complete and restricted to females. Males homozygous for either mutation were capable of mating and producing viable progeny. While AeAct-4 knockout males could fly and mate, their ability to compete for females was reduced compared to wild-type males; this was not the case for loss of myo-fem. Disruption of Aeflightin was associated with loss of flight in both sexes. Phylogenetic analysis of 
AeAct-4 suggests that other mosquito species genomes likely contain female- and malebiased actin genes as well. These data support the pursuit of novel genetic strategies geared specifically for disrupting female flight in Ae. aegypti and other vector species of mosquito.

Materials and Methods

\section{Insect rearing:}

The Liverpool strain of Ae. aegypti was used for embryonic microinjections and outcrossing of mutant individuals. All mosquitoes were reared at $28^{\circ} \mathrm{C}$ and $75-80 \%$ humidity, with a 14/10 h light/dark light cycle. Ground up fish food (Tetra, Blacksburg, VA) was supplied throughout the aquatic developmental stages, and a cotton ball soaked with $10 \%$ sucrose solution was supplied during the adult stage. Flightless mosquitoes were supplied with raisins as the source of sucrose. Defibrinated sheep blood (Colorado Serum Company, Denver, CO) was offered for blood feeding via a parafilm membrane feeder. Videos were taken with a Canon Rebel T3i digital camera.

\section{Computational analysis:}

Publicly available mapped RNA-seq data from Akbari et al. (2013) was retrieved from VectorBase [44]. Raw counts for each gene of interest and all paralogs with $\geq 80 \%$ amino acid similarity were obtained using featureCounts using only uniquely mapped reads [45]. Raw counts data were linear normalized based on transcript length and library size to obtain fragments per kilobase per million reads (FPKM) data. FPKM data were transformed to avoid negative values: $[\log 10(1+\mathrm{FPKM})]$. Transformed data were 
used to generate a heat map with Morpheus (Morpheus, https://software.broadinstitute.org/morpheus). A maximum score of 3.8 was set when generating the heat map based on the highest expression value across all samples/timepoints.

For phylogenetic and molecular evolutionary analyses, VectorBase [44] and FlyBase [46] were used to perform a BLASTP search for orthologs of AeAct-4 and all paralogs with $\geq 80 \%$ amino acid similarity (maximum e-value $1 \mathrm{e}^{-3}$, word size 3 ). All sequences obtained were aligned with MUSCLE [47] and compared using the NeighborJoining method in MEGA version X [48]. Evolutionary distances were computed using the Poisson correction method and are in the units of the number of amino acid substitutions per site. All ambiguous positions were removed for each sequence pair (pairwise deletion option), with a total of 376 positions in the final dataset.

All bar graphs were generated, and Chi square analyses performed, using GraphPad Prism (version 8 for Windows, GraphPad Software, La Jolla, CA, www.graphpad.com).

\section{Guide RNA design and synthesis:}

Guide RNAs were designed by hand with the DNASTAR SeqBuilder Pro software (Madison, WI), using the appropriate gene sequence acquired through VectorBase [44]. Primers used to make each sgRNA were ordered through IDT. Guide RNA synthesis was performed as previously described [34]. Briefly, Q5 High-Fidelity DNA Polymerase (New England BioLabs Inc., Ipswich, MA) was used for the PCR reaction, followed by the NucleoSpin Gel and PCR Clean-Up kit protocol (Machery- 
Nagel, Bethlehem, PA), the MEGAscript T7 Transcription kit protocol, and the MEGAclear Transcription Clean-Up kit protocol (Thermo Fisher Scientific, Waltham, MA). All sgRNAs were quantified, aliquoted, and stored at $-80^{\circ} \mathrm{C}$. A list of oligos used to make each sgRNA are listed in S2 Table.

\section{Embryo microinjections:}

The generation and identification of knockout strains followed essentially from our previously published protocols [49]. Briefly, borosilicate glass capillaries (World Precision Instruments Inc., Sarasota, FL) were pulled and beveled using the Sutter P2000 Micropipette Puller and Sutter BV-10 Micropipette Beveller (Sutter Instrument Co., Novato, CA). Embryo microinjections were performed using a Leica DM 1000 LED Micromanipulator (Leica Biosystems, Buffalo Grove, IL) and FemtoJet 4i Microinjector (Eppendorf, Hauppauge, NY). Purified Cas9 protein (400 ng/ $\mu$ l) (PNA Bio, Thousand Oaks, CA) and sgRNAs (100 ng/ $\mu \mathrm{l})$ were combined into injection mixes, incubated at $37^{\circ} \mathrm{C}$ for 30 minutes, and centrifuged at max speed $(18,213 \mathrm{~g}), 4^{\circ} \mathrm{C}$, for a minimum of 45 minutes. Injections were performed into the posterior end of embryos that were less than three hours old. "AeAct-4 Exp. 1" injection mixes included kmo sgRNAs, while “AeAct-4 B Exp. 2” injection mixes included only site B sgRNAs. Injected embryos were either harvested at 24 hours (for embryo assays) or hatched after five days. Hatched $\mathrm{G}_{0}$ survivors were outcrossed to either the wild type Liverpool strain (for AeAct-4 and myo-fem) or the kmo knockout strain (for Aeflightin). Mutant males (n $=10-25)$ were selected at each subsequent generation for continued outcrossing through $\mathrm{G}_{3}$ (for Aeflightin) or $\mathrm{G}_{5}$ (for AeAct-4 and myo-fem) before intercrosses were performed. 


\section{DNA extraction, PCR, HRMA, and Sanger sequencing:}

Genomic DNA was extracted from non-injected or sgRNA-injected Liverpool embryos following the Nucleospin Tissue kit protocol (Machery-Nagel, Bethlehem, PA). Embryo assays were performed with the LightScanner Master Mix kit (Idaho Technology Inc., Salt Lake City, UT), and mutant detection was performed on adult legs with the Phire Animal Tissue Direct PCR kit (Thermo Fisher Scientific, Waltham, MA) with added LCGreen Plus+ Melting dye (Idaho Technology Inc., Salt Lake City, UT). All samples were amplified with the C1000 Touch Thermal Cycler (Bio-rad, Hercules, CA) before being analyzed with the LightScanner Call-IT 2.0 software on the LightScanner instrument (Idaho Technology Inc., Salt Lake City, UT). Sanger sequencing was performed at the Laboratory for Genomic Technologies (Institute for Plant Genomics and Biotechnology, Texas A\&M University, College Station, TX) and chromatograms were analyzed using Chromas software (Technelysium, Australia). A list of primers used are located in S1 Table.

\section{Flight determination:}

To assess flight, pupae were placed in plastic ketchup containers (with the stick of a cotton swab or Q-tip to aid in escaping from the water due to defects in flight) in 5quart plastic buckets (Home Depot) designed with a mesh covering over the top and a sock for internal access on the side. The plastic lining of the bucket inhibited the mosquitoes from climbing up the sides towards the mesh covering. Flying mosquitoes that could fly up to the mesh covering were removed from the plastic bucket, and 24 hours was allowed to pass after the last pupae emerged before classifying the remaining 
mosquitoes as flightless. Dead adults whose flight phenotype could not be confirmed were not analyzed for a genotype.

\section{Mating competition assays:}

To assess mating competitiveness between wild type and homozygous mutant (AeAct-4 and myo-fem) males, $40 \mathrm{WT} / \mathrm{HOM}$ males (based on HRMA analysis) were placed into a $170 \mathrm{oz}$ container with 40 Liverpool females for mating. After at least 24 hours post-mating, the females were offered a blood meal for a minimum of 30 minutes, and engorged females were selected and separated from males. The EAgaL plate fecundity and fertility assay protocol was followed [50]. Briefly, a single blood fed female was placed in each well of a 24 -well plate that had been prepared by filling each well with agarose. Females were placed at least 72 hours after blood feeding and were given up to 48 hours to deposit embryos. After 48 hours, females were removed, water was added to the wells, and the embryos were monitored over the next 5 days for hatching. If present, 10 or more larval progeny were collected from each individual female that produced embryos. Amplicons derived from the AeAct-4 or myo-fem target sequence from both the male parents and the pooled larval progeny were sequenced to determine the respective starting and resulting genotypes, and thus identify the genotype of the male that mated with the female. At least three biological replicates per mutant strain were performed.

Results 
Since female mosquitoes rely on flight to obtain a blood meal and mate, disrupting flight specifically in females could prevent both reproduction and the transmission of arboviruses. AeAct-4 has been characterized as a female- and pupalspecific flight protein that is expressed in the indirect flight muscles [39]. Indeed, reanalysis of RNA-seq data from the developmental transcriptome of Ae. aegypti [51] confirmed that expression of AeAct-4 was highly biased towards female pupae (S1 Fig). Of the eight paralogous actin genes, six showed expression throughout development and in pupae of both sexes, one (AAEL005964) was pupae-, but not sex-specific, and one (AAEL009451) was expressed specifically in male pupae. AAEL005656 is a paralog to the gene myo-sex (AAEL021838), a male-specific myosin gene located in the M locus on chromosome one [41] and required for male flight [43]. As AAEL005656 was found to be expressed primarily in female pupae (S1 Fig), we reasoned that it might be similarly critical for female flight, and refer to this gene as myo-fem. Finally, AAEL004249 is a 1:1 ortholog of Drosophila melanogaster, flightin, which has been shown to be expressed in the indirect flight muscles [42], with knockout resulting in a loss of flight ability [52]. We refer to this gene as Aeflightin and confirm that it is expressed almost exclusively in pupae in both males and females (S1 Fig). We reasoned that despite lacking female specificity, Aeflightin may be a good target for disrupting female flight, so long as a male-specific rescue can be performed.

For each of these three target genes, we designed multiple groups of overlapping sgRNAs, described in S2 Table with either "site" or "exon" for each group. Due to high nucleotide sequence similarity between AeAct-4 and other actin paralogs, we performed 
a multiple sequence alignment prior to sgRNA design. Eight paralogs with $\geq 80 \%$ nucleotide sequence identity to AeAct-4 were aligned to attempt to identify sgRNA targets that were unique to AeAct-4. Candidate guide RNA sequences were identified in regions where there was more sequence variability between AeAct-4 and the paralogs (S2 Fig). For myo-fem, guide RNAs were designed to target the motor domain to ensure disruption of myosin function. For Aeflightin, guide RNAs were designed to each exon as we did not identify any paralogous genes in the Ae. aegypti genome.

Following in vitro synthesis, sgRNAs were complexed with Cas9 protein and injected in groups of 3-4 into Ae. aegypti embryos, which were harvested after 24 hours. To identify those gRNA batches capable of inducing strong gene disruption, genomic DNA from injected embryos was used as a template for PCR and HRMA of the target region (Fig 1A). For AeAct-4 (Fig 1B), myo-fem (Fig 1C), and Aeflightin (Fig 1D), we identified two clusters of guide RNAs for each gene with detectable editing in embryos.

For each mixture of guide RNAs that displayed editing activity, we repeated embryo microinjections and this time allowed the embryos to hatch after five days. Survivors were outcrossed to the parental Liverpool strain to obtain $\mathrm{G}_{1}$ progeny. $\mathrm{G}_{1}$ adults were screened via PCR, HRMA, and Sanger sequencing for out-of-frame mutations (S3 Table). Deletions predicted to result in a frameshift mutation were recovered for AeAct-4, myo-fem, and Aeflightin (Fig 2A). Genotyped males with out-offrame mutations $(\mathrm{n}=10-25)$ were outcrossed to females from the parental strain for three (for Aeflightin) or five (for AeAct-4 and myo-fem) generations, followed by 
A

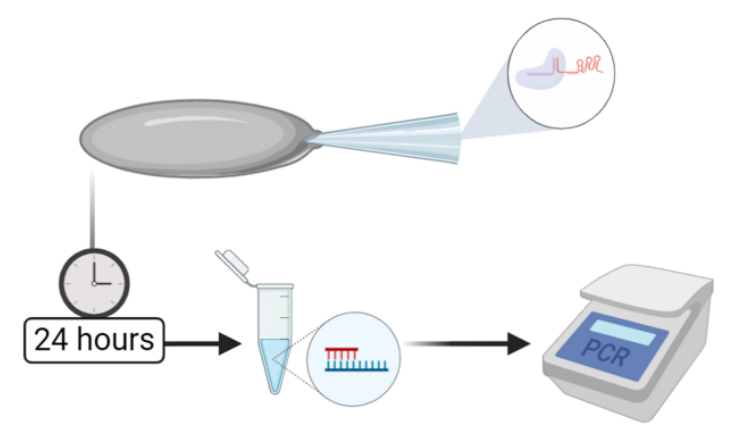

C
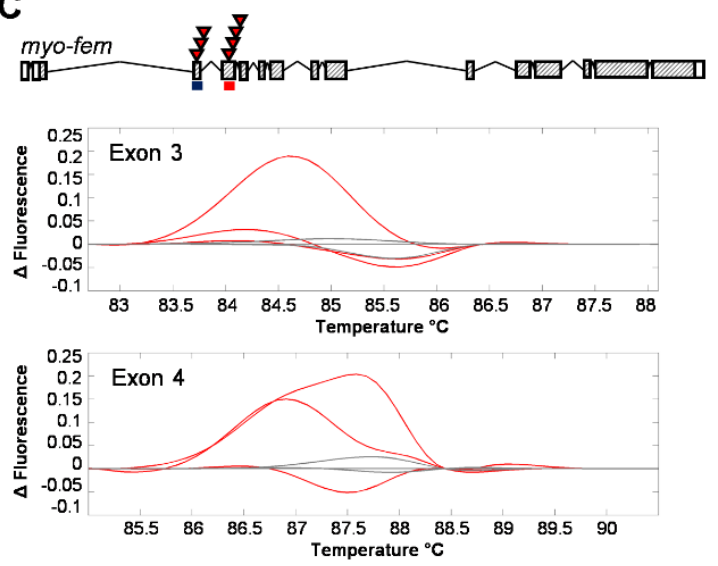

$\square$ Non-injected LVP embryos
B
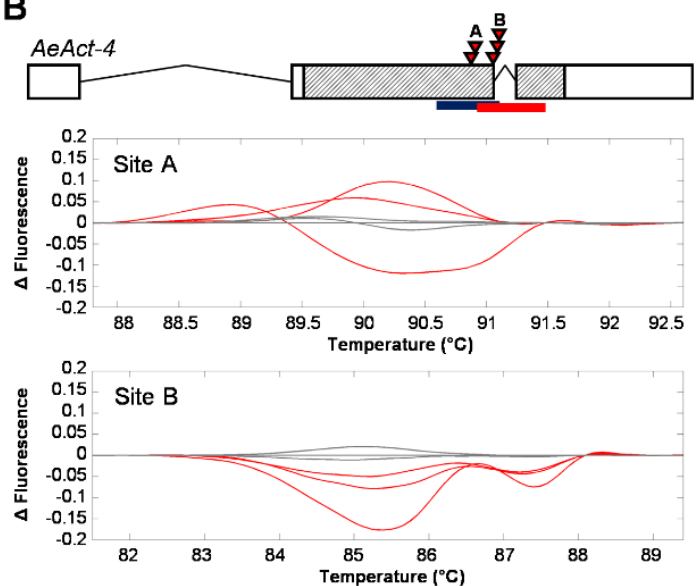

D
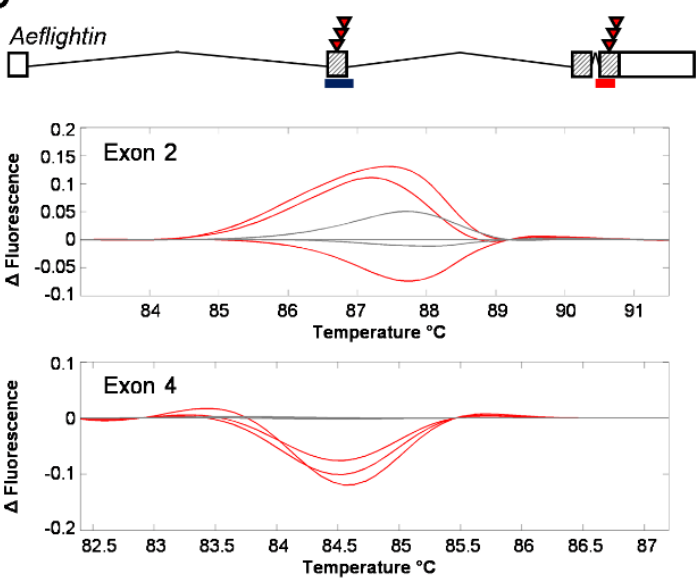

$\square$ sgRNA-injected LVP embryos

Fig 1. Development of CRISPR reagents targeting Ae. aegypti genes involved in flight.

(A) Workflow for performing embryo assays. Gene models and HRMA analysis following embryonic microinjection of CRISPR/Cas9 reagents with each group of sgRNAs for AeAct-4 (B), myo-fem (C), and Aeflightin (D). For (B-D), boxes represent exons, while cross-hatched areas represent the ORF of the corresponding mRNA. For each, red triangles indicate the locations of sgRNAs that were found to successfully cleave the DNA during embryo assay, and the blue and red boxes under the gene models indicate the approximate HRMA amplicon sizes. Melt curves are displayed for clusters of sgRNAs (indicated as "site" or "exon"), with sgRNA-injected (red) and non-injected (gray) samples.

intercrosses of heterozygous individuals (Fig 2B and 2C). Backcrossing of the mutant strains was performed to reduce any CRISPR/Cas9 off-target effects and assist in the 
recovery from the genetic bottleneck associated with single founder events. AeAct-4 is located on chromosome three, as are three other actin paralogs (AAEL001928, AAEL005961, and AAEL005964). Therefore, we performed Sanger sequencing of each actin paralog to confirm that there were no off-target effects in these paralogs linked to AeAct-4, as these may have been maintained despite backcrossing ( $\mathrm{S} 3 \mathrm{Fig}$ ). $\mathrm{G}_{6}$ progeny from heterozygous intercrosses were characterized as flightless or flying (Fig 3A and S4 Table). Upon stimulation of flight, control mosquitoes could fly, while some from each test cross could not; these were therefore categorized as flightless and hypothesized to be homozygous for each targeted gene disruption. Flightless individuals appeared to have various alternative wing phenotypes when resting that differed from wild type (Fig 3BE). Some individuals could move or beat their wings, but with no success in flight. Other individuals could initiate flight takeoff, but not sustain flight. Agitation to provoke flight via shaking or tapping of the plastic buckets (S1-S3 Videos), or gentle spraying of 


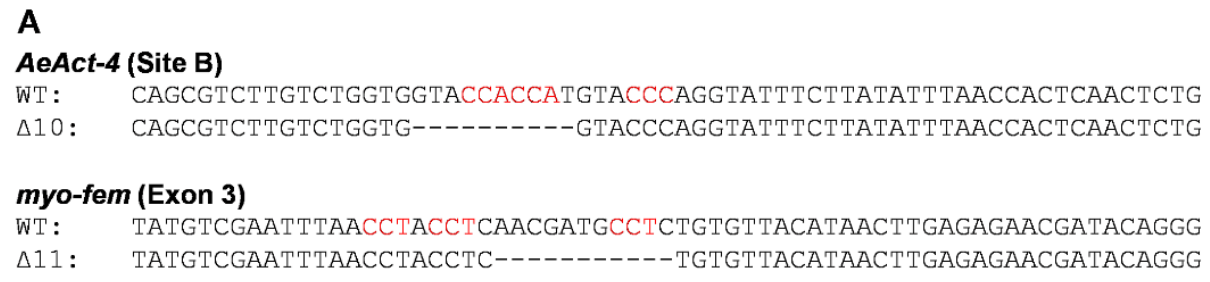

B

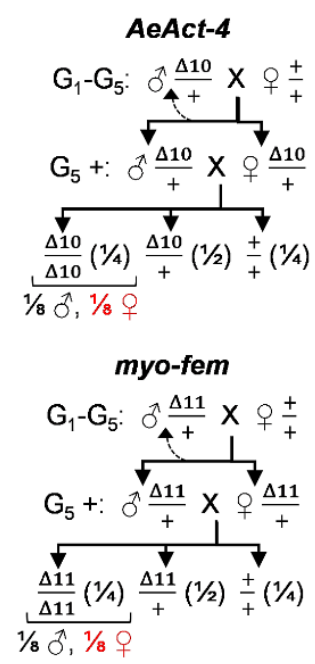

C

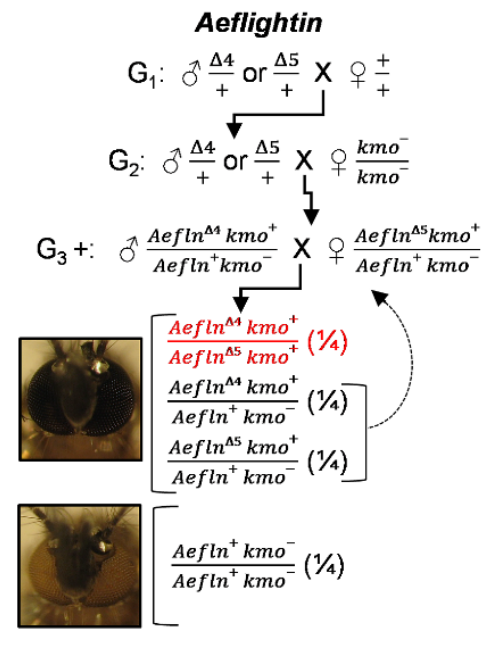

Fig 2. Establishment and maintenance of heritable loss-of-function mutations in Ae. aegypti flight genes.

(A) For each gene, the wild type (WT) and mutant sequence is shown. The PAM sites for each sgRNA used in the injection mix for the specified location are highlighted in red. Individuals containing each deletion were outcrossed through the indicated generation, at which point individuals heterozygous for the AeAct-4, myo-fem (B), and Aeflightin (C) mutations were intercrossed. For each cross, the ratio of each potential genotype expected is noted in parentheses, with the individuals with an expected flightless phenotype highlighted in red. For Aeflightin, phenotypic identification of all white-eyed pupae enables their removal before further phenotypic analysis based on flight (see Fig 4) is performed.

condensed air were used to evaluate flight ability; flightless mosquitoes remained so regardless of the method of stimulation. 
As all observations of flight behavior were made without consideration for genotype, we sought to determine whether there was a relationship between the ability of mosquitoes to fly and inheriting one or two copies of each loss-of-function mutation. A genotypic analysis of all flightless individuals and a subset of flying individuals was performed for AeAct4 and myo-fem (S4 Table and Fig 3F and 3G) as well as Aeflightin (S5 Table and Fig 3H). All AeAct-4 $4^{410 / \Delta 10}$ males and all myo-fem ${ }^{411 / \Delta 11}$ males except one (S4 Table) could fly $($ AeAct-4 $=100 \% ;$ myo-fem $=96 \%)$, while all AeAct-4 $4^{410 / 410}$ and myo-fem ${ }^{\Delta 11 / \Delta 11}$ females were flightless (100\%). Interestingly, while most heterozygous AeAct $-4^{410 /+}$ females could fly (97\%, only two were flightless), this was not the case for myo-fem ${ }^{\Delta 11 /+}$, where about half of females $(53 \%)$ were categorized as flightless. The flying to flightless ratio did not differ significantly from the expected ratio for AeAct-4 ( $p=0.6503$, Chi square analysis), suggesting the flightless phenotype was completely recessive in this case. Due to the presence of a substantial number of flightless heterozygous females for myo-fem (46 individuals) as compared to AeAct-4 (2 individuals), the flying to flightless ratio was significantly different from the expected ratio ( $\mathrm{p}<0.0001$, Chi square analysis), suggesting that defects in myo-fem are not entirely recessive. From the intercross between AeAct- $4^{410 /+}$ parents, we observed that male genotype ratios of WT, heterozygous, and homozygous individuals did not differ from the null expectation, suggesting a lack of strong fitness cost to males associated with the mutation ( $\mathrm{p}=0.6628$, Chi square analysis). In contrast, we observed a deficiency of homozygous males and a corresponding excess of heterozygotes for myo- 

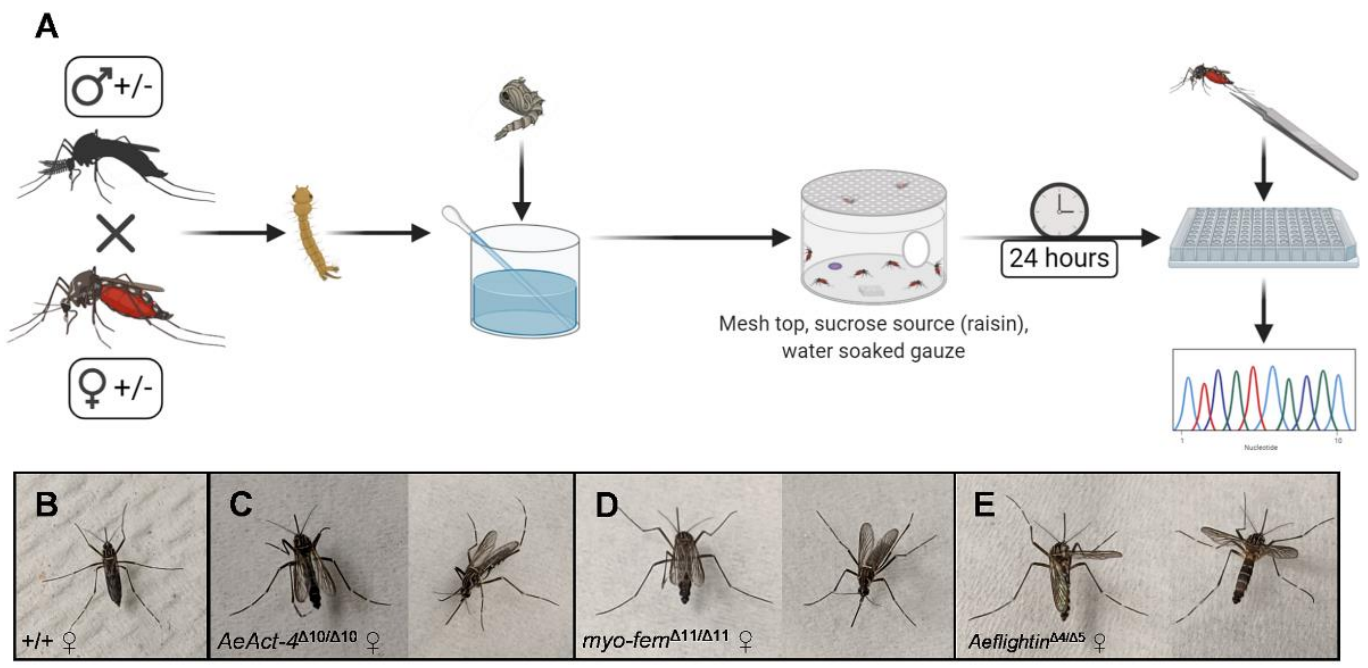

$\mathbf{F}$

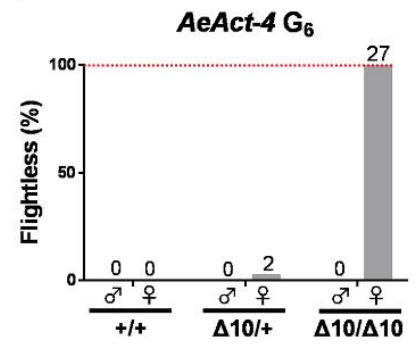

G

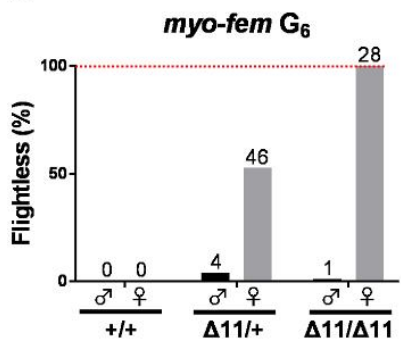

$\mathrm{H}$

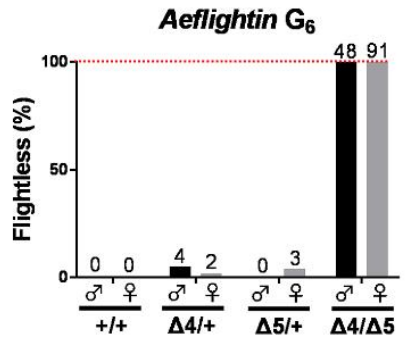

Fig 3. Loss of AeAct-4, myo-fem, or Aeflightin results in flightlessness.

(A) Blinded workflow used to score flight ability without experimenter knowledge of genotype, with subsequent genotyping assays. Photographs of wild type (B), AeAct- $4^{410 / \Delta 10}(\mathbf{C})$, myo-fem ${ }^{411 / \Delta 11}(\mathbf{D})$, or Aeflightin $^{4 / 1 / 45}(\mathbf{E})$ females when resting. The percentage of flightless male (black bars) or female (grey bars) mosquitoes for AeAct-4 (F), myo-fem $(\mathbf{G})$, and Aeflightin $(\mathbf{H})$ based on each genotype. The number above each bar represents the number of individuals displaying the flightless phenotype and were confirmed for the specified genotype via sequencing. The dotted red line indicates $100 \%$ flightless.

fem ( $\mathrm{p}=0.0008$, Chi square analysis). As the Aeflightin gene is tightly linked to the kmo gene involved in eye pigmentation, Aeflightin mutants were outcrossed to a kynurenine 3-monooxygenase ( $\mathrm{kmo}$ ) knockout strain [34] to help track the corresponding genotypes. This aided in phenotypic identification of homozygous kmo individuals who do not carry the Aeflightin mutation, as well as maintenance of a transheterozygous line (Fig 2C). At 
G6, recombination between kmo and Aeflightin was observed at 1-3\%, consistent with expectations (S5 Table). After scoring flight phenotypes, genotypes were determined by HRMA and sequencing. Critically, we found that all transheterozygous Aeflightin ${ }^{44 / \Delta 5}$ individuals were flightless, confirming that Aeflightin is required for flight in both male and female Ae. aegypti (Fig 3 and S5 Table). The flying to flightless ratio did not differ significantly from the expected ratio for Aeflightin ( $\mathrm{p}=0.5319$, Chi square analysis), suggesting that a single copy of Aeflightin is sufficient to program flight, and the associated flightless phenotype is recessive.

As we noted that both AeAct-4 and myo-fem are expressed at low levels in male pupae [51] (S1 Fig), we hypothesized that this may indicate these genes contribute to male flight. While our loss-of-function data suggest these gene products are not required for flight, we reasoned that they may still contribute to male mating success, which occurs in flight. Thus, we sought to compare the mating competitiveness between wild type and homozygous mutant males, an important consideration if these genes are to be potential targets in a genetic control approach such as gene drive. We took advantage of the fact that wild type and homozygous individuals cannot be distinguished by HRMA alone in our assay (requires sequencing) to perform a series of blinded mating competition experiments. After screening by HRMA, 40 males with WT/HOM genotypes were crossed with 40 wild type females. After 1-3 days, females were offered a bloodmeal and progeny were collected from each female individually. At the same time, all HRMA amplicons were sequenced to obtain the starting percentage of each male genotype. In the case of a mating between a WT male and a WT female, all 
progeny would be WT, while matings between homozygous mutant males and WT females should result in progeny heterozygous for the mutation (either AeAct $-4^{410}$ or $\left.m y o-f e m^{411}\right)$. HRMA and sequencing analysis was used to determine the genotype of the larval progeny, and thus, the genotype of the individual male that mated with that female (Fig 4A). Wild type males significantly outperformed AeAct- $4^{410 / 410}$ males in mating with wild type females (Fig 4B; AeAct-4 $\mathrm{p}=0.0018$, Chi square analysis), suggesting that AeAct-4 may contribute to the mating success of male Ae. aegypti. In contrast, for myo-fem (Fig 4C) the difference in mating success was not significantly different from expectations based on starting genotypes (myo-fem $\mathrm{p}=0.0805$, Chi square analysis). We note that we did not monitor the females for remating events, thus it is possible that mutant individuals are less competitive than indicated. We also note that for myo-fem, there was more variation in the data than for AeAct-4, and this may serve to obscure real differences in competitiveness. Data for each replicate experiment is presented individually (S6 Table), along with the expected and observed larval progeny genotypes. 


\section{A}

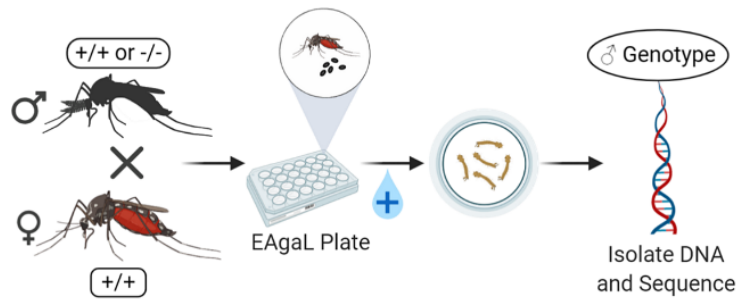

B

C
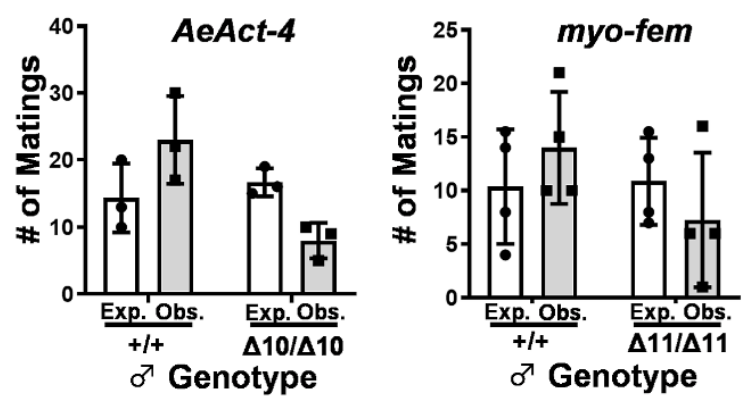

Fig 4. Mating competitiveness of male Ae. aegypti deficient in AeAct-4 or myo-fem.

(A) Workflow for performing larval progeny assays. The observed (Obs.) vs. expected (Exp.) number of matings for AeAct-4 (B) and myo-fem (C) males based on the sequenced genotypes of pooled larval progeny obtained from the male mating competitiveness assays. Wild type is defined as $+/+$ and homozygous mutants are defined as $\Delta 10 / \Delta 10$ (for AeAct-4) or $\Delta 11 / \Delta 11$ (for myo-fem). Each data point represents one replicate, bar height represents the mean of all replicates, and the error bars indicate standard deviation. Chi square was performed for statistical analysis.

After successfully knocking out flight-associated genes in Ae. aegypti, we were interested in finding out if other mosquito genomes contain sex-specific flight genes.

Previous phylogenetic analysis of the male-specific myo-sex suggests that both maleand female-specific myosin flight genes evolved in Aedes after divergence from Culex [41]. To determine if this was also the case for AeAct-4, we performed a phylogenetic analysis of actin protein sequences across multiple mosquito species, as well as the fruit fly Drosophila melanogaster (Fig 5). Both AeAct-4 and the male-biased actin gene 
AAEL009451 clustered separately with orthologs from Ae. albopictus, Culex, and Anopheles mosquitoes, suggesting a more ancient origin to these sex-biased genes. Consistent with this reconstruction, the An. gambiae gene AGAP011515 grouped with AeAct-4 and was previously found to be preferentially expressed in females [53], while AGAP001676 groups with the Aedes male actin gene, and was also found to have significantly increased expression in the male carcass (head, thorax, and abdomen, excluding the reproductive tissue) as compared to the female carcass [54]. Together, these data suggest that genetic approaches targeting flight specifically in females may be broadly applicable across mosquito genera. 


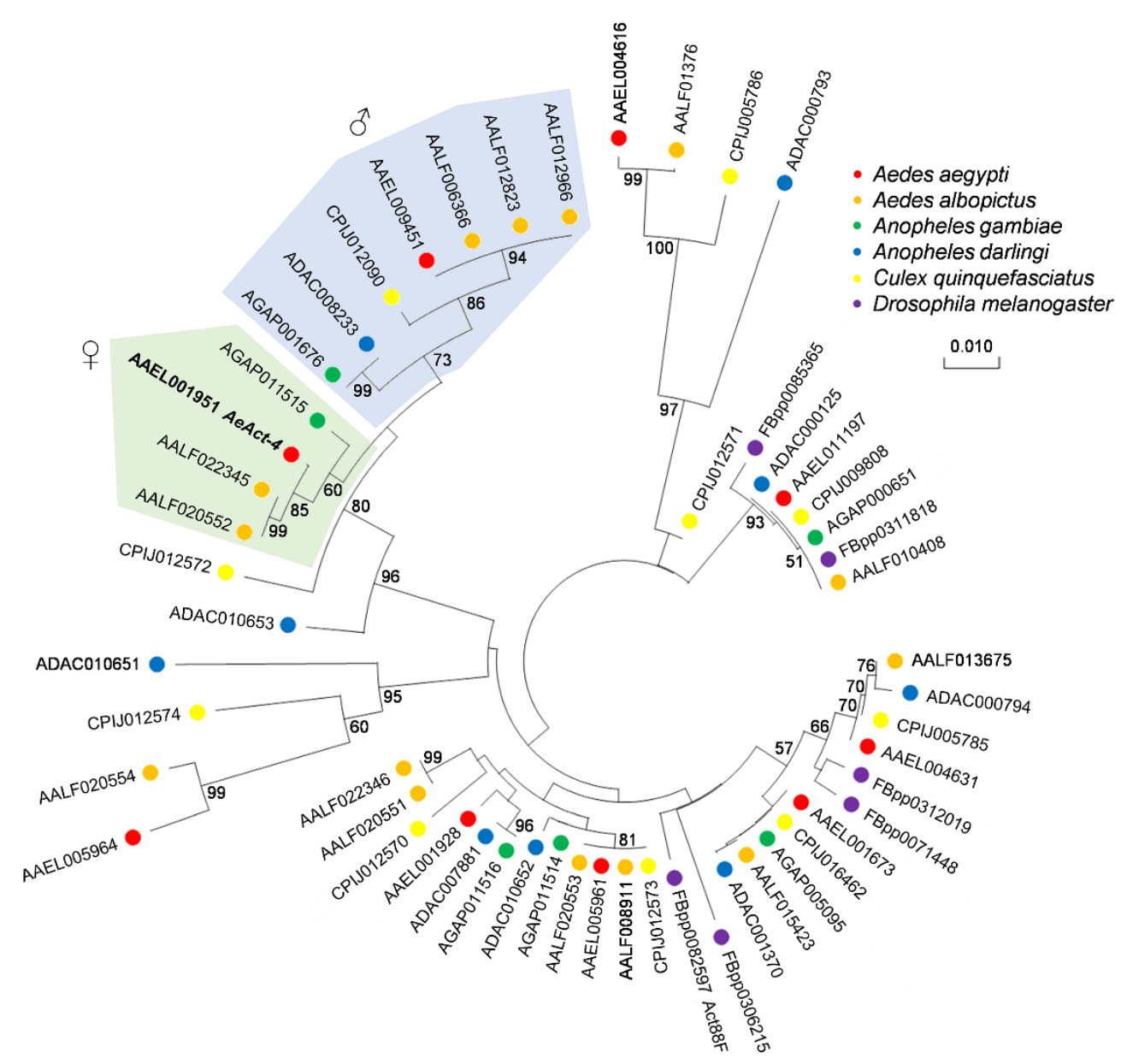

Fig 5. Neighbor-joining tree of AeAct-4 and related homologs in mosquitoes.

A phylogenetic analysis of AeAct-4 (in bold face) and all paralogs with $\geq 80 \%$ amino acid similarity in mosquitoes and Drosophila. The gene identifiers include Ae. aegypti (AAEL in red), Ae. albopictus (AALF in orange), An. gambiae (AGAP in green), An. darlingi (ADAC in blue), Cu. quinquefasciatus (CPIJ in yellow), and D. melanogaster (FBpp in purple). Female-specific genes are represented in the green shaded area, and male-specific genes are in the blue shaded area. All branch points with $>50 \%$ support based on 1,000 bootstrap replicates are indicated. 


\section{Discussion}

Our results indicate successful knockout of three flight-specific genes, two of which are expressed predominantly in females (AeAct-4 and myo-fem). Interestingly, we found that while AeAct-4 and Aeflightin were haplosufficient, two intact copies of myofem appeared to be required for normal female flight. We note though that our approach allowed 24 hours after the last adult emerged for all mosquitoes to gain the ability to fly. For myo-fem, there were a few individuals who subsequently gained the ability to fly up to 48 hours after all flyers had been removed. These individuals seemed to have a delay ( $\geq 24$ hours post-eclosion) in gaining flight ability, suggesting that a single copy of myofem, while insufficient to program the normal timing of development of the flight muscles, may be sufficient provided the female can survive long enough. If myo-fem is truly haploinsufficient, this opens the door for the development of strong synthetic sex distorters for suppressing Ae. aegypti populations [22,55-61]. Despite the lack of female specificity for the third gene, Aeflightin, we reason that this still represents a useful target so long as a male-specific rescue can be performed to fully restore male flight.

Flightless Ae. aegypti have been developed previously through the transgenic overexpression of the tTa transactivator specifically in the female flight muscle [62]. In this case, the promoter region of AeAct-4 was used to control transgene expression, however transgenic males were found to have decreased mating competitiveness in field cage trials $[63,64]$. Variability in the level of transgene overexpression also resulted in incomplete penetrance of the flightless phenotype. In our case, disruption of both the AeAct-4 gene and the myo-fem gene through heritable gene editing resulted in a 
completely penetrant phenotype without the requirement for continuous transgene expression as previously seen with AeAct-4. As both AeAct-4 and myo-fem show low levels of transcription in male pupae [51], we hypothesized that disruption of both genes would lead to reduced flight in males beyond observable differences, such as mating competitiveness. Indeed, males with mutations in AeAct-4 exhibit decreased levels of mating when compared to wild type males. Though this decrease was not observed in males with mutations in myo-fem, we interpret these data with caution due to the confined nature of the mating experiment (170 oz. container), and that despite outcrossing mutants for multiple generations, there is a possibility of a genetic bottleneck leading to reduced fitness in males, regardless of these flight gene knockouts. More rigorous follow-up experiments in larger venues that require more flight effort from test males (in larger quantities and ratios of wild type to homozygous) are likely required to conclude that myo-fem is dispensable for male mating success. Male and female Ae. aegypti are known to produce different flight tones, which are shifted to match frequencies during mating; this harmonic convergence could be a measure of male reproductive fitness [65-68] and could be heritable [69]. It is plausible that AeAct-4 and myo-fem contribute towards modulating wing beat frequency in males; future experiments to investigate this using the mutant strains developed here may shed light on this interesting aspect of Ae. aegypti biology.

Disrupting flight specifically in female mosquitoes could be used to achieve sex ratio distortion of the adult population. This is conceptually similar to other sex distortion approaches such as the X-shredding system based on the I-PpoI homing 
endonuclease when active only during male meiosis, which has shown to be capable of producing $>95 \%$ male progeny $[56,60,70,71]$ and has been introgressed from $A n$. gambiae to An. arabiensis [72]. Other examples of targets for sex ratio distortion in $A n$. gambiae include female reproductive genes [29,57-59] and the female transcript of doublesex, which causes an intersex phenotype and complete sterility [59], however the recessive nature of these phenotypes reduces their power as sex distorters. In Drosophila melanogaster, disruption of other genes causing female fertility or embryonic lethality [22] have been shown to skew the sex ratio towards males, as does knockdown of tra-2 in Ae. aegypti [61]. Meanwhile, overexpression of the male sex determining factor nix has been proposed as a method of sex distortion in Ae. aegypti [55]. Population modeling has also been evaluated when considering resistance that can evolve when using a driving Y for sex ratio distortion [73]. We note that the development of a sex ratio distortion approach that targets female-specific flight would allow for maximum competition for resources during larval development as well as allow active monitoring of the number of females doomed to flightlessness, while at the same time preventing the adult female from reproducing and potentially transmitting deadly pathogens. A gene drive-based sex ratio distortion approach targeting these female-specific flight genes could be implemented if males were carriers of the gene drive and released into the wild to mate with females, such that all female progeny would be affected and not survive to blood feed and transmit pathogens; all male progeny would inherit the transgene and continue to survive and mate at each subsequent generation (Fig 6). Such strategies to target sex-specific flight genes are likely to be applicable to other species of mosquito 
including Culex and Anopheles, as these mosquitoes also appear to encode sex-specific flight genes.

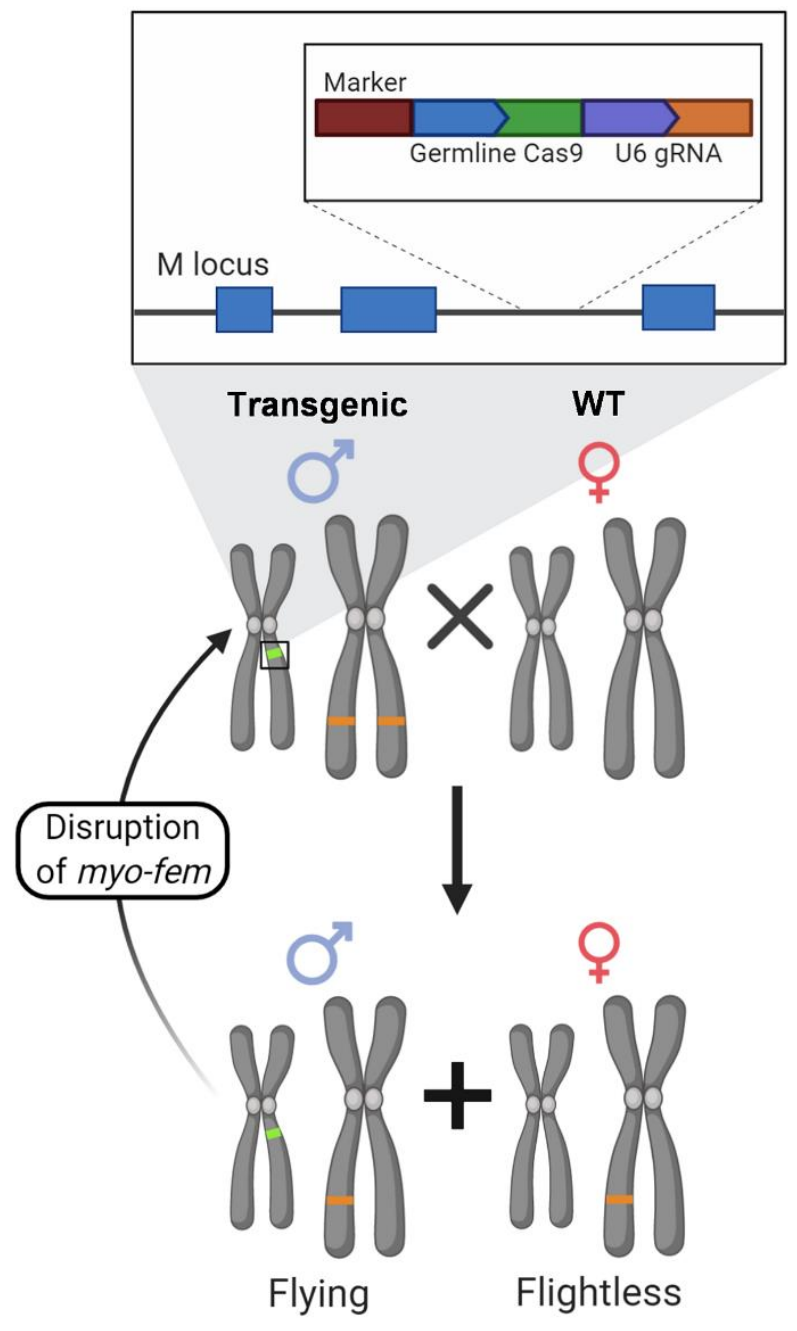

Fig 6. An M-locus-linked sex distorter gene drive targeting female-specific flight genes.

Male mosquitoes modified to contain a site specific nuclease targeting a haploinsufficient female flight gene (myo-fem) in the M-locus would be released to mate with wild type females. All male progeny from these matings would inherit the nuclease, which would inactivate the intact female flight gene inherited from the mother. All female progeny from these matings would inherit one disrupted allele of the femalespecific flight gene and therefore be unable to fly, blood feed, or mate to produce future offspring. 


\section{References}

1. CDC. Surveillance and Control of Aedes aegypti and Aedes albopictus in the United States. 2017.

2. CDC. Mosquito life cycle. 2018.

3. Zettel C, Kaufman P. Yellow fever mosquito Aedes aegypti (Linnaeus) (Insecta: Diptera: Culicidae). Featured Creatures [Internet]. 2009:[8 p.].

4. Thieler M, Smith, H. H. The effect of prolonged cultivation in vitro upon the pathogenicity of yellow fever virus. J Exp Med. 1937;65:767-86.

5. CDC. Help Control Mosquitoes that Spread Dengue, Chikungunya, and Zika Viruses. 2015.

6. Clemons A, Haugen M, Flannery E, Tomchaney M, Kast K, Jacowski C, et al. Aedes aegypti: an emerging model for vector mosquito development. Cold Spring Harb Protoc. 2010;2010(10):pdb emo141. Epub 2010/10/05. doi: 10.1101/pdb.emo141. PubMed PMID: 20889691; PubMed Central PMCID: PMCPMC2975269.

7. Alphey L. Genetic control of mosquitoes. Annual review of entomology. 2014;59:205-24. doi: 10.1146/annurev-ento-011613-162002. PubMed PMID: 24160434. 8. Alphey L, Nimmo D, O'Connell S, Alphey N. Insect Population Suppression Using Engineered Insects. New York, New York: Landes Bioscience and Spring Science+Business Media; 2008.

9. Bond JG, Osorio AR, Avila N, Gomez-Simuta Y, Marina CF, Fernandez-Salas I, et al. Optimization of irradiation dose to Aedes aegypti and Ae. albopictus in a sterile insect technique program. PLoS One. 2019;14(2):e0212520. Epub 2019/02/20. doi: 
10.1371/journal.pone.0212520. PubMed PMID: 30779779; PubMed Central PMCID: PMCPMC6380561.

10. McGraw EA, O'Neill SL. Beyond insecticides: new thinking on an ancient problem. Nat Rev Microbiol. 2013;11(3):181-93. Epub 2013/02/16. doi:

10.1038/nrmicro2968. PubMed PMID: 23411863.

11. Kandul NP, Liu J, Sanchez CH, Wu SL, Marshall JM, Akbari OS. Transforming insect population control with precision guided sterile males with demonstration in flies. Nat Commun. 2019;10(1):84. Epub 2019/01/10. doi: 10.1038/s41467-018-07964-7. PubMed PMID: 30622266; PubMed Central PMCID: PMCPMC6325135.

12. Zheng X, Zhang D, Li Y, Yang C, Wu Y, Liang X, et al. Incompatible and sterile insect techniques combined eliminate mosquitoes. Nature. 2019;572(7767):56-61. Epub 2019/07/19. doi: 10.1038/s41586-019-1407-9. PubMed PMID: 31316207.

13. Gilles JR, Schetelig MF, Scolari F, Marec F, Capurro ML, Franz G, et al. Towards mosquito sterile insect technique programmes: exploring genetic, molecular, mechanical and behavioural methods of sex separation in mosquitoes. Acta Trop. 2014;132 Suppl:S178-87. Epub 2013/09/03. doi: 10.1016/j.actatropica.2013.08.015. PubMed PMID: 23994521.

14. Akbari OS, Bellen HJ, Bier E, Bullock SL, Burt A, Church GM, et al. BIOSAFETY. Safeguarding gene drive experiments in the laboratory. Science. 2015;349(6251):927-9. Epub 2015/08/01. doi: 10.1126/science.aac7932. PubMed PMID: 26229113; PubMed Central PMCID: PMCPMC4692367. 
15. Akbari OS, Matzen KD, Marshall JM, Huang H, Ward CM, Hay BA. A synthetic gene drive system for local, reversible modification and suppression of insect populations. Current biology : CB. 2013;23(8):671-7. doi: 10.1016/j.cub.2013.02.059. PubMed PMID: 23541732.

16. Buchman A, Gamez S, Li M, Antoshechkin I, Li HH, Wang HW, et al. Broad dengue neutralization in mosquitoes expressing an engineered antibody. PLoS Pathog. 2020;16(1):e1008103. Epub 2020/01/17. doi: 10.1371/journal.ppat.1008103. PubMed PMID: 31945137; PubMed Central PMCID: PMCPMC6964813 J.E.C. has served as a consultant for Takeda Vaccines, Sanofi Pasteur, Pfizer, and Novavax, is on the Scientific Advisory Boards of CompuVax, GigaGen, Meissa Vaccines, and is the Founder of IDBiologics, Inc. All other authors declare no competing financial interests.

17. Buchman A, Gamez S, Li M, Antoshechkin I, Li HH, Wang HW, et al. Engineered resistance to Zika virus in transgenic Aedes aegypti expressing a polycistronic cluster of synthetic small RNAs. Proceedings of the National Academy of Sciences of the United States of America. 2019;116(9):3656-61. Epub 2019/02/07. doi: 10.1073/pnas.1810771116. PubMed PMID: 30723148; PubMed Central PMCID: PMCPMC6397566.

18. Buchman AB, Ivy T, Marshall JM, Akbari OS, Hay BA. Engineered Reciprocal Chromosome Translocations Drive High Threshold, Reversible Population Replacement in Drosophila. ACS Synth Biol. 2018;7(5):1359-70. Epub 2018/04/03. doi:

10.1021/acssynbio.7b00451. PubMed PMID: 29608276. 
19. Gantz VM, Jasinskiene N, Tatarenkova O, Fazekas A, Macias VM, Bier E, et al. Highly efficient Cas9-mediated gene drive for population modification of the malaria vector mosquito Anopheles stephensi. Proceedings of the National Academy of Sciences of the United States of America. 2015;112(49):E6736-43. doi:

10.1073/pnas.1521077112. PubMed PMID: 26598698; PubMed Central PMCID: PMCPMC4679060.

20. Hammond AM, Kyrou K, Gribble M, Karlsson X, Morianou I, Galizi R, et al. Improved CRISPR-based suppression gene drives mitigate resistance and impose a large reproductive load on laboratory-contained mosquito populations. bioRxiv. 2018. doi: $10.1101 / 360339$.

21. KaramiNejadRanjbar M, Eckermann KN, Ahmed HMM, Sanchez CH, Dippel S, Marshall JM, et al. Consequences of resistance evolution in a Cas9-based sex conversion-suppression gene drive for insect pest management. Proceedings of the National Academy of Sciences of the United States of America. 2018;115(24):6189-94. doi: 10.1073/pnas.1713825115. PubMed PMID: 29844184; PubMed Central PMCID: PMCPMC6004448.

22. Oberhofer G, Ivy T, Hay BA. Behavior of homing endonuclease gene drives targeting genes required for viability or female fertility with multiplexed guide RNAs. Proceedings of the National Academy of Sciences of the United States of America. 2018;115(40):E9343-E52. doi: 10.1073/pnas.1805278115. PubMed PMID: 30224454; PubMed Central PMCID: PMCPMC6176634. 
23. Sinkins SP, Gould F. Gene drive systems for insect disease vectors. Nature reviews Genetics. 2006;7(6):427-35. doi: 10.1038/nrg1870. PubMed PMID: 16682981. 24. Noble C, Min J, Olejarz J, Buchthal J, Chavez A, Smidler AL, et al. Daisy-chain gene drives for the alteration of local populations. Proceedings of the National Academy of Sciences of the United States of America. 2019;116(17):8275-82. Epub 2019/04/04. doi: 10.1073/pnas.1716358116. PubMed PMID: 30940750; PubMed Central PMCID: PMCPMC6486765.

25. Oberhofer G, Ivy T, Hay BA. Cleave and Rescue, a novel selfish genetic element and general strategy for gene drive. Proceedings of the National Academy of Sciences of the United States of America. 2019;116(13):6250-9. doi: 10.1073/pnas.1816928116.

PubMed PMID: 30760597; PubMed Central PMCID: PMCPMC6442612.

26. Unckless RL, Clark AG, Messer PW. Evolution of Resistance Against CRISPR/Cas9 Gene Drive. Genetics. 2017;205(2):827-41. doi:

10.1534/genetics.116.197285. PubMed PMID: 27941126; PubMed Central PMCID: PMCPMC5289854.

27. Champer J, Liu J, Oh SY, Reeves R, Luthra A, Oakes N, et al. Reducing resistance allele formation in CRISPR gene drive. Proceedings of the National Academy of Sciences of the United States of America. 2018;115(21):5522-7. doi:

10.1073/pnas.1720354115. PubMed PMID: 29735716; PubMed Central PMCID: PMCPMC6003519.

28. Champer J, Reeves R, Oh SY, Liu C, Liu J, Clark AG, et al. Novel CRISPR/Cas9 gene drive constructs reveal insights into mechanisms of resistance allele 
formation and drive efficiency in genetically diverse populations. PLoS genetics. 2017;13(7):e1006796. doi: 10.1371/journal.pgen.1006796. PubMed PMID: 28727785; PubMed Central PMCID: PMCPMC5518997.

29. Hammond AM, Kyrou K, Bruttini M, North A, Galizi R, Karlsson X, et al. The creation and selection of mutations resistant to a gene drive over multiple generations in the malaria mosquito. PLoS genetics. 2017;13(10):e1007039. doi:

10.1371/journal.pgen.1007039. PubMed PMID: 28976972; PubMed Central PMCID: PMCPMC5648257.

30. Yan Y, Finnigan GC. Development of a multi-locus CRISPR gene drive system in budding yeast. Sci Rep. 2018;8(1):17277. Epub 2018/11/24. doi: 10.1038/s41598018-34909-3. PubMed PMID: 30467400; PubMed Central PMCID: PMCPMC6250742. 31. Port F, Bullock SL. Augmenting CRISPR applications in Drosophila with tRNAflanked sgRNAs. Nat Methods. 2016;13(10):852-4. Epub 2016/09/07. doi: 10.1038/nmeth.3972. PubMed PMID: 27595403; PubMed Central PMCID: PMCPMC5215823.

32. Xie K, Minkenberg B, Yang Y. Boosting CRISPR/Cas9 multiplex editing capability with the endogenous tRNA-processing system. Proceedings of the National Academy of Sciences of the United States of America. 2015;112(11):3570-5. Epub 2015/03/04. doi: 10.1073/pnas.1420294112. PubMed PMID: 25733849; PubMed Central PMCID: PMCPMC4371917.

33. Jinek M, Chylinski K, Fonfara I, Hauer M, Doudna JA, Charpentier E. A programmable dual-RNA-guided DNA endonuclease in adaptive bacterial immunity. 
Science. 2012;337(6096):816-21. doi: 10.1126/science.1225829. PubMed PMID: 22745249 .

34. Basu S, Aryan A, Overcash JM, Samuel GH, Anderson MA, Dahlem TJ, et al. Silencing of end-joining repair for efficient site-specific gene insertion after TALEN/CRISPR mutagenesis in Aedes aegypti. Proceedings of the National Academy of Sciences of the United States of America. 2015;112(13):4038-43. doi:

10.1073/pnas.1502370112. PubMed PMID: 25775608; PubMed Central PMCID: PMC4386333.

35. Kistler KE, Vosshall LB, Matthews BJ. Genome engineering with CRISPR-Cas9 in the mosquito Aedes aegypti. Cell reports. 2015;11(1):51-60. doi:

10.1016/j.celrep.2015.03.009. PubMed PMID: 25818303; PubMed Central PMCID: PMC4394034.

36. Chaverra-Rodriguez D, Macias VM, Hughes GL, Pujhari S, Suzuki Y, Peterson DR, et al. Targeted delivery of CRISPR-Cas9 ribonucleoprotein into arthropod ovaries for heritable germline gene editing. Nat Commun. 2018;9(1):3008. Epub 2018/08/03. doi: 10.1038/s41467-018-05425-9. PubMed PMID: 30068905; PubMed Central PMCID: PMCPMC6070532.

37. Li M, Bui M, Yang T, Bowman CS, White BJ, Akbari OS. Germline Cas9 expression yields highly efficient genome engineering in a major worldwide disease vector, Aedes aegypti. Proceedings of the National Academy of Sciences of the United States of America. 2017;114(49):E10540-E9. doi: 10.1073/pnas.1711538114. PubMed PMID: 29138316; PubMed Central PMCID: PMCPMC5724270. 
38. Li M, Yang T, Kandul NP, Bui M, Gamez S, Raban R, et al. Development of a Confinable Gene-Drive System in the Human Disease Vector, Aedes aegypti. 2019. doi: $10.1101 / 645440$.

39. Muñoz D, Jimenez A, Marinotti O, James AA. The AeAct-4 gene is expressed in the developing flight muscles of female Aedes aegypti. Insect molecular biology. 2004;13(5):563-8.

40. Vyazunova I, Lan Q. Stage-specific expression of two actin genes in the yellow fever mosquito, Aedes aegypti. Insect molecular biology. 2004;13(5):241-9.

41. Hall AB, Timoshevskiy VA, Sharakhova MV, Jiang X, Basu S, Anderson MA, et al. Insights into the preservation of the homomorphic sex-determining chromosome of Aedes aegypti from the discovery of a male-biased gene tightly linked to the M-locus. Genome biology and evolution. 2014;6(1):179-91. doi: 10.1093/gbe/evu002. PubMed PMID: 24398378; PubMed Central PMCID: PMC3914700.

42. Vigoreaux JO. Flightin, a novel myofibrillar protein of Drosophila stretchactivated muscles. The Journal of Cell Biology. 1993;121(3):587-98. doi: 10.1083/jcb.121.3.587.

43. Aryan A, Anderson M, Biedler JK, Qi Y, Overcash JM, Naumenko AN, et al. Nix confers heritable sex-conversion in Aedes aegypti and myo-sex is needed for male flight. bioRxiv. 2019. doi: 10.1101/595371.

44. Giraldo-Calderon GI, Emrich SJ, MacCallum RM, Maslen G, Dialynas E, Topalis P, et al. VectorBase: an updated bioinformatics resource for invertebrate vectors and other organisms related with human diseases. Nucleic acids research. 
2015;43(Database issue):D707-13. doi: 10.1093/nar/gku1117. PubMed PMID: 25510499; PubMed Central PMCID: PMCPMC4383932.

45. Liao Y, Smyth GK, Shi W. featureCounts: an efficient general purpose program for assigning sequence reads to genomic features. Bioinformatics. 2014;30(7):923-30. doi: 10.1093/bioinformatics/btt656. PubMed PMID: 24227677.

46. Thurmond J, Goodman JL, Strelets VB, Attrill H, Gramates LS, Marygold SJ, et al. FlyBase 2.0: the next generation. Nucleic Acids Res. 2019;47(D1):D759-D65. Epub 2018/10/27. doi: 10.1093/nar/gky1003. PubMed PMID: 30364959; PubMed Central PMCID: PMCPMC6323960.

47. Edgar RC. MUSCLE: multiple sequence alignment with high accuracy and high throughput. Nucleic Acids Res. 2004;32(5):1792-7. Epub 2004/03/23. doi:

10.1093/nar/gkh340. PubMed PMID: 15034147; PubMed Central PMCID: PMCPMC390337.

48. Kumar S, Stecher G, Li M, Knyaz C, Tamura K. MEGA X: Molecular Evolutionary Genetics Analysis across Computing Platforms. Mol Biol Evol. 2018;35(6):1547-9. Epub 2018/05/04. doi: 10.1093/molbev/msy096. PubMed PMID: 29722887; PubMed Central PMCID: PMCPMC5967553.

49. Aryan A, Myles KM, Adelman ZN. Targeted genome editing in Aedes aegypti using TALENs. Methods. 2014;69(1):38-45. doi: 10.1016/j.ymeth.2014.02.008. PubMed PMID: 24556554; PubMed Central PMCID: PMC4136995.

50. Tsujimoto H, Adelman ZN. Improved Fecundity and Fertility Assay for Aedes aegypti Using 24 Well Tissue Culture Plates (EAgaL Plates). JoVE. 2020 (in press). 
51. Akbari OS, Antoshechkin I, Amrhein H, Williams B, Diloreto R, Sandler J, et al. The developmental transcriptome of the mosquito Aedes aegypti, an invasive species and major arbovirus vector. G3. 2013;3(9):1493-509. doi: 10.1534/g3.113.006742. PubMed PMID: 23833213; PubMed Central PMCID: PMC3755910.

52. Reedy MC, Bullard B, Vigoreaux JO. Flightin Is Essential for Thick Filament Assembly and Sarcomere Stability inDrosophilaFlight Muscles. The Journal of Cell Biology. 2000;151(7):1483-500. doi: 10.1083/jcb.151.7.1483.

53. Marinotti O, Calvo E, Nguyen QK, Dissanayake S, Ribeiro JMC, James AA. Genome-wide analysis of gene expression in adult Anopheles Gambiae. Insect molecular biology. 2006;15(1):1-12. doi: 10.1111/j.1365-2583.2006.00610.

54. Papa F, Windbichler N, Waterhouse RM, Cagnetti A, D'Amato R, Persampieri T, et al. Rapid evolution of female-biased genes among four species of Anopheles malaria mosquitoes. Genome Res. 2017;27(9):1536-48. Epub 2017/07/28. doi:

10.1101/gr.217216.116. PubMed PMID: 28747381; PubMed Central PMCID: PMCPMC5580713.

55. Adelman ZN, Tu Z. Control of Mosquito-Borne Infectious Diseases: Sex and Gene Drive. Trends in parasitology. 2016;32(3):219-29. doi: 10.1016/j.pt.2015.12.003. PubMed PMID: 26897660; PubMed Central PMCID: PMCPMC4767671.

56. Galizi R, Doyle LA, Menichelli M, Bernardini F, Deredec A, Burt A, et al. A synthetic sex ratio distortion system for the control of the human malaria mosquito. Nature communications. 2014;5:3977. doi: 10.1038/ncomms4977. PubMed PMID: 24915045 ; PubMed Central PMCID: PMC4057611. 
57. Galizi R, Hammond A, Kyrou K, Taxiarchi C, Bernardini F, O'Loughlin SM, et al. A CRISPR-Cas9 sex-ratio distortion system for genetic control. Scientific reports. 2016;6:31139. doi: 10.1038/srep31139. PubMed PMID: 27484623; PubMed Central PMCID: PMCPMC4971495.

58. Hammond A, Galizi R, Kyrou K, Simoni A, Siniscalchi C, Katsanos D, et al. A CRISPR-Cas9 gene drive system targeting female reproduction in the malaria mosquito vector Anopheles gambiae. Nature biotechnology. 2016;34(1):78-83. doi:

10.1038/nbt.3439. PubMed PMID: 26641531; PubMed Central PMCID:

PMCPMC4913862.

59. Kyrou K, Hammond AM, Galizi R, Kranjc N, Burt A, Beaghton AK, et al. A CRISPR-Cas9 gene drive targeting doublesex causes complete population suppression in caged Anopheles gambiae mosquitoes. Nature biotechnology. 2018;36(11):1062-6. doi: 10.1038/nbt.4245. PubMed PMID: 30247490; PubMed Central PMCID: PMCPMC6871539.

60. Windbichler N, Papathanos PA, Crisanti A. Targeting the X chromosome during spermatogenesis induces Y chromosome transmission ratio distortion and early dominant embryo lethality in Anopheles gambiae. PLoS genetics. 2008;4(12):e1000291. Epub 2008/12/06. doi: 10.1371/journal.pgen.1000291. PubMed PMID: 19057670; PubMed Central PMCID: PMCPMC2585807.

61. Hoang KP, Teo TM, Ho TX, Le VS. Mechanisms of sex determination and transmission ratio distortion in Aedes aegypti. Parasit Vectors. 2016;9:49. Epub 
2016/01/29. doi: 10.1186/s13071-016-1331-x. PubMed PMID: 26818000; PubMed Central PMCID: PMCPMC4730765.

62. Fu G, Lees RS, Nimmo D, Aw D, Jin L, Gray P, et al. Female-specific flightless phenotype for mosquito control. Proceedings of the National Academy of Sciences of the United States of America. 2010;107(10):4550-4. doi: 10.1073/pnas.1000251107. PubMed PMID: 20176967; PubMed Central PMCID: PMC2826341.

63. Facchinelli L, Valerio L, Ramsey JM, Gould F, Walsh RK, Bond G, et al. Field cage studies and progressive evaluation of genetically-engineered mosquitoes. PLoS neglected tropical diseases. 2013;7(1):e2001. doi: 10.1371/journal.pntd.0002001. PubMed PMID: 23350003; PubMed Central PMCID: PMC3547837.

64. Wise de Valdez MR, Nimmo D, Betz J, Gong HF, James AA, Alphey L, et al. Genetic elimination of dengue vector mosquitoes. Proceedings of the National Academy of Sciences of the United States of America. 2011;108(12):4772-5. doi:

10.1073/pnas.1019295108. PubMed PMID: 21383140; PubMed Central PMCID: PMC3064365.

65. Cator LJ, Arthur BJ, Harrington LC, Hoy RR. Harmonic convergence in the love songs of the dengue vector mosquito. Science. 2009;323(5917):1077-9. Epub 2009/01/10. doi: 10.1126/science.1166541. PubMed PMID: 19131593; PubMed Central PMCID: PMCPMC2847473.

66. Arthur BJ, Emr KS, Wyttenbach RA, Hoy RR. Mosquito (Aedes aegypti) flight tones: frequency, harmonicity, spherical spreading, and phase relationships. J Acoust 
Soc Am. 2014;135(2):933-41. Epub 2014/09/23. doi: 10.1121/1.4861233. PubMed PMID: 25234901; PubMed Central PMCID: PMCPMC3985972.

67. Aldersley A, Cator LJ. Female resistance and harmonic convergence influence male mating success in Aedes aegypti. Sci Rep. 2019;9(1):2145. Epub 2019/02/16. doi: 10.1038/s41598-019-38599-3. PubMed PMID: 30765779; PubMed Central PMCID: PMCPMC6375921.

68. Cator LJ, Zanti Z. Size, sounds and sex: interactions between body size and harmonic convergence signals determine mating success in Aedes aegypti. Parasit Vectors. 2016;9(1):622. Epub 2016/12/03. doi: 10.1186/s13071-016-1914-6. PubMed PMID: 27906074; PubMed Central PMCID: PMCPMC5133739.

69. Cator LJ, Harrington LC. The Harmonic Convergence of Fathers Predicts the Mating Success of Sons in Aedes aegypti. Anim Behav. 2011;82(4):627-33. Epub 2011/10/18. doi: 10.1016/j.anbehav.2011.07.013. PubMed PMID: 22003255; PubMed Central PMCID: PMCPMC3190198.

70. Klein TA, Windbichler N, Deredec A, Burt A, Benedict MQ. Infertility resulting from transgenic I-PpoI male Anopheles gambiae in large cage trials. Pathog Glob Health. 2012;106(1):20-31. Epub 2012/05/19. doi: 10.1179/2047773212Y.0000000003. PubMed PMID: 22595271.

71. Fasulo B, Meccariello A, Morgan M, Borufka C, Papathanos PA, Windbichler N. A fly model establishes distinct mechanisms for synthetic CRISPR/Cas9 sex distorters. PLoS Genet. 2020;16(3):e1008647. Epub 2020/03/14. doi: 
10.1371/journal.pgen.1008647. PubMed PMID: 32168334; PubMed Central PMCID: PMCPMC7108745.

72. Bernardini F, Kriezis A, Galizi R, Nolan T, Crisanti A. Introgression of a synthetic sex ratio distortion system from Anopheles gambiae into Anopheles arabiensis. Sci Rep. 2019;9(1):5158. Epub 2019/03/28. doi: 10.1038/s41598-019-41646-8. PubMed PMID: 30914785; PubMed Central PMCID: PMCPMC6435806.

73. Beaghton A, Beaghton PJ, Burt A. Vector control with driving Y chromosomes: modelling the evolution of resistance. Malar J. 2017;16(1):286. Epub 2017/07/15. doi: 10.1186/s12936-017-1932-7. PubMed PMID: 28705249; PubMed Central PMCID: PMCPMC5513332. 


\section{APPENDIX}

\section{Figures}

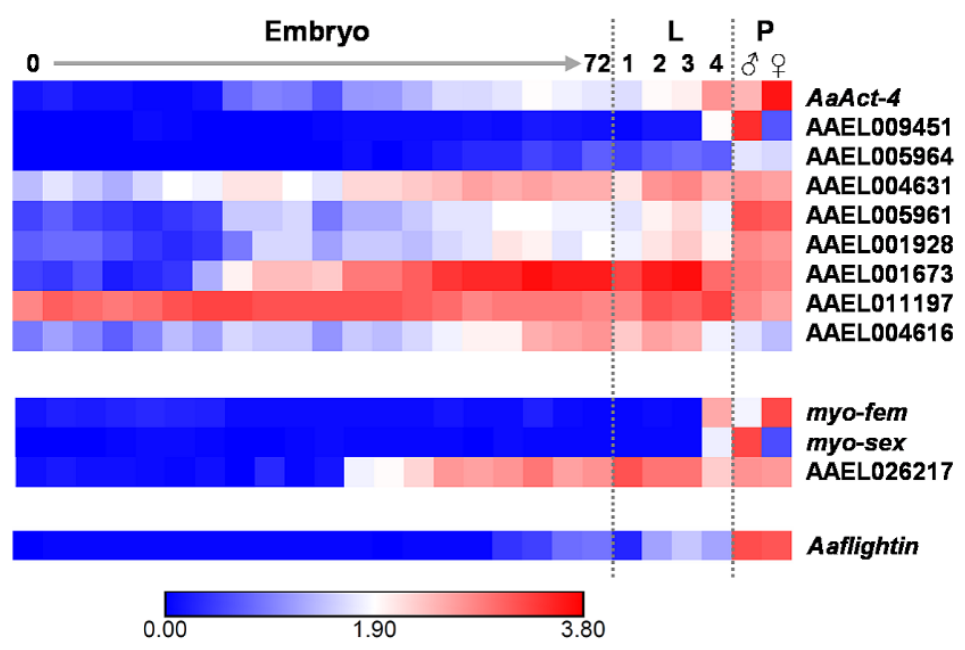

S1 Fig. Developmental expression profile of Ae. aegypti actin, myosin, and flightin genes.

Heat map showing the expression of AeAct-4, myo-fem, and Aeflightin, as well as all paralogs with $\geq 80 \%$ amino acid similarity. Gene names/identifiers are listed on the right, with the developmental time points indicated above, as described by Akbari et al. [51]. Scale represents absolute expression as $\log _{10}$ $(\mathrm{FPKM}+1)$.

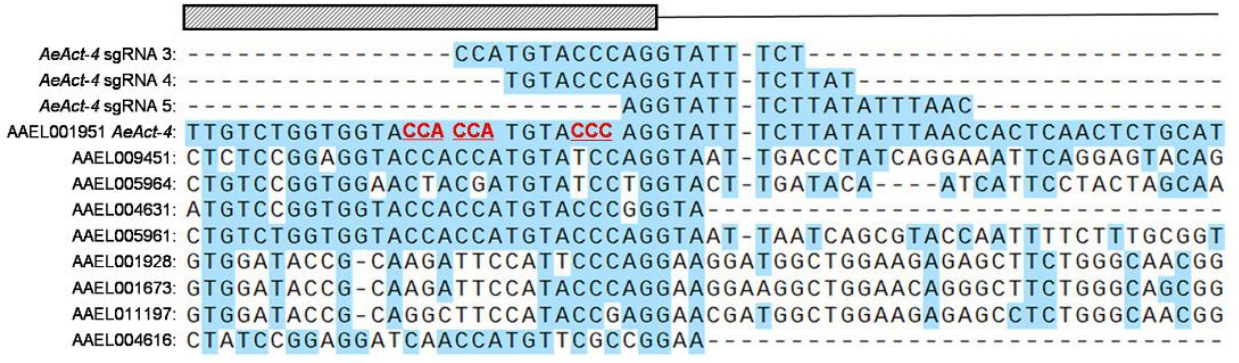

S2 Fig. Alignment of AeAct-4 and paralogs for sgRNA design.

Nucleotide alignment of AeAct-4 and eight paralogs with $>80 \%$ nucleotide similarity. Identical nucleotides at each position are highlighted in blue; the gene model above the alignment shows the exon (box)/intron (line) boundary. Included at the top of the alignment are three sgRNAs that induced disruptions in AeAct4 , with the PAM sites emphasized in underlined red text. 


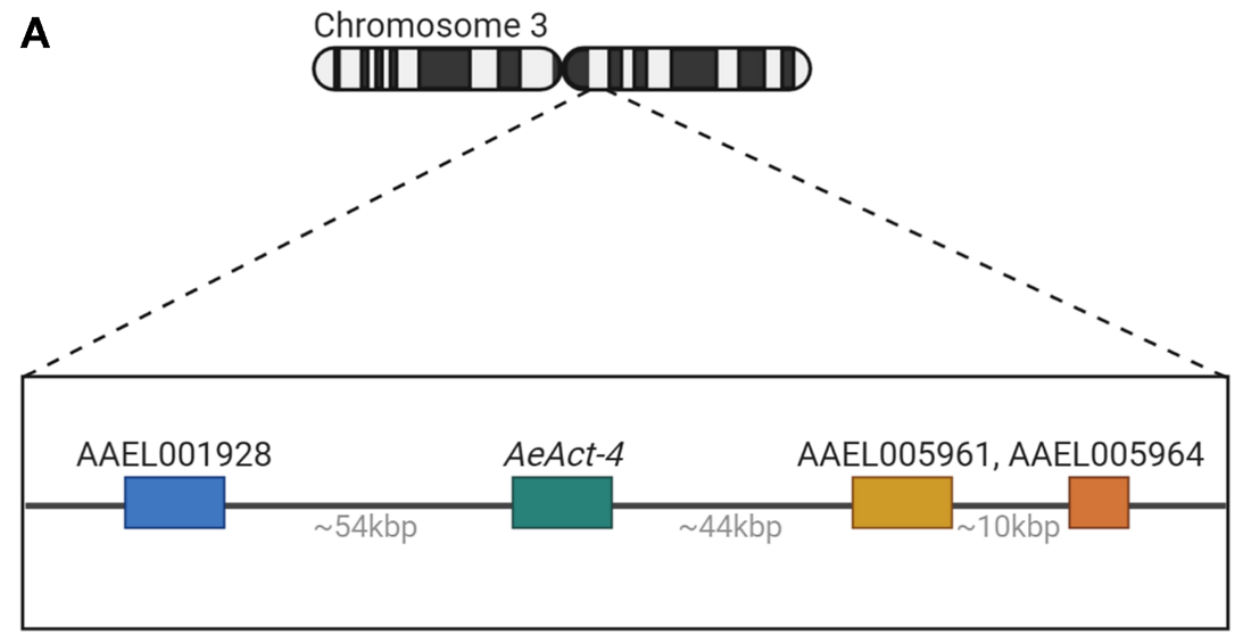

B

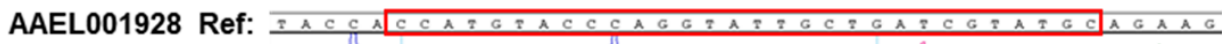
Sample 1

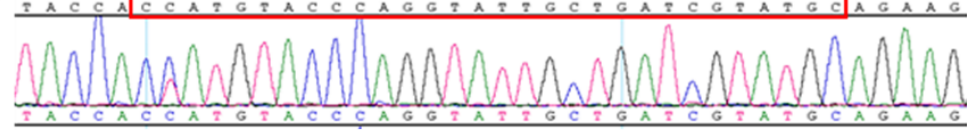

C

AAEL005961 Ref:

Sample 1

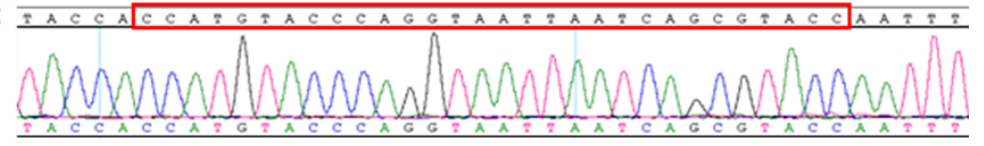

D

AAEL005964 Ref:

Sample 1

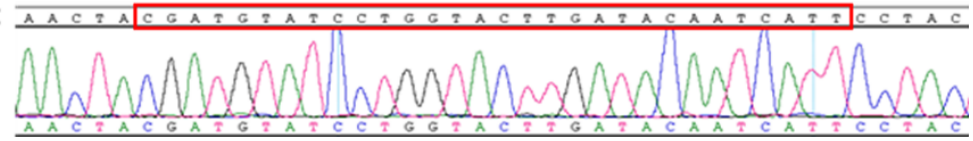

S3 Fig. Locations and sequencing results of closely linked paralogs to AeAct-4.

(A) Three actin paralogs located near AeAct-4 on chromosome three that were of interest to check for offtarget effects. Sanger sequencing results focused around the hypothesized sgRNA target areas (indicated with a red box) based on the actin paralog alignment for AAEL001928 (B), AAEL005961 (C), and AAEL005964 (D). 


\section{Tables}

S1 Table. Primer sequences. Oligonucleotide sequences used for PCR amplification of each gene.

\begin{tabular}{|c|c|c|}
\hline Gene & Sequence & Primer use/location \\
\hline AeAct-4 & CCACCGCTGAACGTGAAATCGTTCG & Primer, embryo assay, site A \\
\hline AeAct-4 & AGAAATACCTGGGTACATGGTG & Primer, embryo assay, site A \\
\hline AeAct- 4 & GGATCTCTATGCTAACAGCGTCTTGTC & Primer, embryo assay, site B \\
\hline AeAct-4 & TAGCTTGGAAGGTAGACAGC & Primer, embryo assay, site B \\
\hline AeAct- 4 & ATCCTTCCTGGGAATGGAATCAACT & Primer, site B \\
\hline AeAct- 4 & CTGCTTGGAGATCCACATAGCT & Primer, site B \\
\hline myo-fem & TATACTTACATAGATCAGCC & Primer, exon 3 \\
\hline myo-fem & TGCCGCAGACCAAGGATTTC & Primer, exon 3 \\
\hline myo-fem & CCTGATCTTCCAGGGACGGC & Primer, exon 4 \\
\hline myo-fem & TGTACACGTTGCGAGTCGCC & Primer, exon 4 \\
\hline myo-fem & CACCGACGGCATTGTAGACC & Primer, exon 7 \\
\hline myo-fem & GAAGCCTTCGATATCTTAGG & Primer, exon 7 \\
\hline Aeflightin & GTTCGACTACCAACTCACCG & Primer, exon 2 \\
\hline Aeflightin & TTCAGAAATAAGCGCTCGTG & Primer, exon 2 \\
\hline Aeflightin & CTCTCAGTTCGCAGGACACG & Primer, exon 3 \\
\hline Aeflightin & ATGAAACAAATTACAGCCCG & Primer, exon 3 \\
\hline Aeflightin & GCTGTTAAGATAGCGCTTCG & Primer, exon 4 \\
\hline Aeflightin & ACTAATTCAAGTGAACTCAC & Primer, exon 4 \\
\hline AAEL001928 & ATCCTTCCTGGGAATGGAATCAACT & Primer \\
\hline AAEL001928 & CCTATTCTTCAGGATTAACTTAGAAGC & Primer \\
\hline AAEL005961 & ATCCTTCCTGGGAATGGAATCTGCT & Primer \\
\hline AAEL005961 & CGCAAAGAAAATTGGTACGC & Primer \\
\hline AAEL005964 & ATCGTTCTTGGGCATGGAAACGGCA & Primer \\
\hline AAEL005964 & GGTGCAACGGCGGTTATCTCT & Primer \\
\hline
\end{tabular}


S2 Table. Guide RNA sequences. Oligonucleotide sequences used to synthesize sgRNAs for CRISPRediting of each gene.

\begin{tabular}{|c|c|c|}
\hline Gene & Sequence & Guide RNA location \\
\hline AeAct-4 & $\begin{array}{c}\text { GAAATTAATACGACTCACTATAGG } \\
\text { GGGAAGTTCATAAGACTTCT GTTTTAGAGCTAGAAA }\end{array}$ & Guide RNA, site A \\
\hline AeAct-4 & $\begin{array}{c}\text { GAAATTAATACGACTCACTATAGG } \\
\text { ATCAACTGGCATTCATGAAA GTTTTAGAGCTAGAAA }\end{array}$ & Guide RNA, site A \\
\hline AeAct-4 & $\begin{array}{c}\text { GAAATTAATACGACTCACTATAGG } \\
\text { AGAAATACCTGGGTACATGG GTTTTAGAGCTAGAAA }\end{array}$ & Guide RNA, site B \\
\hline AeAct-4 & $\begin{array}{c}\text { GAAATTAATACGACTCACTATAGG } \\
\text { ATAAGAAATACCTGGGTACA GTTTTAGAGCTAGAAA }\end{array}$ & Guide RNA, site B \\
\hline AeAct-4 & $\begin{array}{c}\text { GAAATTAATACGACTCACTATAGG } \\
\text { GTTAAATATAAGAAATACCT GTTTTAGAGCTAGAAA }\end{array}$ & Guide RNA, site B \\
\hline myo-fem & $\begin{array}{c}\text { GAAATTAATACGACTCACTATAGG } \\
\text { TCTCAAGTTATGTAACACAG GTTTTAGAGCTAGAAA }\end{array}$ & Guide RNA, exon 3 \\
\hline myo-fem & $\begin{array}{c}\text { GAAATTAATACGACTCACTATAGG } \\
\text { GTAACACAGAGGCATCGTTG GTTTTAGAGCTAGAAA }\end{array}$ & Guide RNA, exon 3 \\
\hline myo-fem & $\begin{array}{c}\text { GAAATTAATACGACTCACTATAGG } \\
\text { CACAGAGGCATCGTTGAGGT GTTTTAGAGCTAGAAA }\end{array}$ & Guide RNA, exon 3 \\
\hline myo-fem & $\begin{array}{c}\text { GAAATTAATACGACTCACTATAGG } \\
\text { AAAAACTGAAAACACAAAGA GTTTTAGAGCTAGAAA }\end{array}$ & Guide RNA, exon 4 \\
\hline myo-fem & $\begin{array}{c}\text { GAAATTAATACGACTCACTATAGG } \\
\text { TTTTCCTGCACCAGACTCGC GTTTTAGAGCTAGAAA }\end{array}$ & Guide RNA, exon 4 \\
\hline myo-fem & $\begin{array}{c}\text { GAAATTAATACGACTCACTATAGG } \\
\text { ATTACCGGCGAGTCTGGTGC GTTTTAGAGCTAGAAA }\end{array}$ & xon 4 \\
\hline myo-fem & $\begin{array}{c}\text { GAAATTAATACGACTCACTATAGG } \\
\text { ATGTTGATTACCGGCGAGTC GTTTTAGAGCTAGAAA }\end{array}$ & Guide RNA, exon 4 \\
\hline myo-fem & $\begin{array}{c}\text { GAAATTAATACGACTCACTATAGG } \\
\text { TAAACTGCTGGGTTGCGTTA GTTTTAGAGCTAGAAA }\end{array}$ & Guide RNA, exon 7 \\
\hline myo-fem & $\begin{array}{c}\text { GAAATTAATACGACTCACTATAGG } \\
\text { AACCCAGCAGTTTAGCGACT GTTTTAGAGCTAGAAA }\end{array}$ & Guide RNA, exon 7 \\
\hline myo-fem & $\begin{array}{c}\text { GAAATTAATACGACTCACTATAGG } \\
\text { GACCGAGTCGCTAAACTGCT GTTTTAGAGCTAGAAA }\end{array}$ & Guide RNA, exon 7 \\
\hline myo-fem & $\begin{array}{c}\text { GAAATTAATACGACTCACTATAGG } \\
\text { GTCACCTTCTTCTATGCCAT GTTTTAGAGCTAGAAA }\end{array}$ & Guide RNA, exon 7 \\
\hline Aeflightin & $\begin{array}{c}\text { GAAATTAATACGACTCACTATAGG } \\
\text { AAGTCATCGACAATGTCTAG GTTTTAGAGCTAGAAA }\end{array}$ & Guide RNA, exon 2 \\
\hline Aeflightin & $\begin{array}{c}\text { GAAATTAATACGACTCACTATAGG } \\
\text { TGTCTAGCGGCTCCGCTCCG GTTTTAGAGCTAGAAA }\end{array}$ & Guide RNA, exon 2 \\
\hline Aeflightin & $\begin{array}{c}\text { GAAATTAATACGACTCACTATAGG } \\
\text { GGTGAAAAATACCCGCGGAG GTTTTAGAGCTAGAAA }\end{array}$ & Guide RNA, exon 2 \\
\hline Aeflightin & $\begin{array}{c}\text { GAAATTAATACGACTCACTATAGG } \\
\text { AGACGGGCTCGCGGAATGCC GTTTTAGAGCTAGAAA }\end{array}$ & Guide RNA, exon 3 \\
\hline Aeflightin & $\begin{array}{c}\text { GAAATTAATACGACTCACTATAGG } \\
\text { TTCCGCGAGCCCGTCTGTCC GTTTTAGAGCTAGAAA } \\
\end{array}$ & Guide RNA, exon 3 \\
\hline Aeflightin & $\begin{array}{c}\text { GAAATTAATACGACTCACTATAGG } \\
\text { TGATGACGTCATAGATTACC GTTTTAGAGCTAGAAA }\end{array}$ & Guide RNA, exon 3 \\
\hline Aeflightin & $\begin{array}{c}\text { GAAATTAATACGACTCACTATAGG } \\
\text { ATCCCGCTTCAATCCGATGT GTTTTAGAGCTAGAAA }\end{array}$ & Guide RNA, exon 4 \\
\hline Aeflightin & $\begin{array}{c}\text { GAAATTAATACGACTCACTATAGG } \\
\text { ATGTTGGTGTAGTTGTACAT GTTTTAGAGCTAGAAA }\end{array}$ & Guide RNA, exon 4 \\
\hline Aeflightin & $\begin{array}{c}\text { GAAATTAATACGACTCACTATAGG } \\
\text { TACATTTCGTCGATGCTCTT GTTTTAGAGCTAGAAA }\end{array}$ & Guide RNA, exon 4 \\
\hline
\end{tabular}


S3 Table. Generation of loss-of-function mutants in Ae. aegypti flight genes using CRISPR/Cas9. Raw data from embryonic injections of CRISPR/Cas9 reagents targeting from each gene.

\begin{tabular}{|c|c|c|c|c|c|c|c|}
\hline Line & $\begin{array}{c}\# \\
\text { Injected }\end{array}$ & $\begin{array}{c}\text { \# Go } \\
\text { Hatched }\end{array}$ & $\begin{array}{c}\% \mathbf{G}_{0} \\
\text { Survival }\end{array}$ & $\begin{array}{c}\mathbf{G}_{1} \\
\text { Genotyped }\end{array}$ & $\begin{array}{c}\# \mathbf{G}_{1} \\
\text { Sequenced }\end{array}$ & $\begin{array}{c}\text { \# G1 } \\
\text { Mutants }\end{array}$ & Results \\
\hline $\begin{array}{l}\text { AeAct-4 } \\
\text { Exp. } 1\end{array}$ & 407 & 83 & $20.4 \%$ & 240 & 19 & 2 & $\Delta 3$ \\
\hline $\begin{array}{c}\text { myo-fem } \\
\text { Exon } 3 \\
\text { Exp. } 1 \\
\end{array}$ & 468 & 43 & $9.2 \%$ & 320 & 20 & 9 & $\begin{array}{c}4 \Delta 4, \Delta 3, \\
\text { i } 2, \Delta 11\end{array}$ \\
\hline $\begin{array}{c}\text { myo-fem } \\
\text { Exon } 4 \\
\text { Exp. } 1\end{array}$ & 455 & $\begin{array}{l}54 \\
\end{array}$ & $11.9 \%$ & 197 & 6 & 0 & N/A \\
\hline $\begin{array}{l}\text { Aeflightin } \\
\text { Exon } 2 \\
\text { Exp. } 1 \\
\end{array}$ & 373 & 49 & $13.1 \%$ & 80 & 10 & 2 & $\Delta 9$ \\
\hline $\begin{array}{c}\text { Aeflightin } \\
\text { Exon } 4 \\
\text { Exp. } 1 \\
\end{array}$ & 353 & 57 & $16.2 \%$ & 240 & 4 & 2 & $\Delta 3$ \\
\hline $\begin{array}{c}\text { myo-fem } \\
\text { Exon } 4 \\
\text { Exp. } 2 \\
\end{array}$ & 265 & 29 & $11.0 \%$ & 80 & 0 & 0 & N/A \\
\hline $\begin{array}{l}\text { Aeflightin } \\
\text { Exon } 2 \\
\text { Exp. } 2\end{array}$ & 362 & 114 & $31.5 \%$ & 240 & 23 & 15 & $\begin{array}{c}\Delta 2 \Delta 5 \mathrm{a}, \\
\Delta 5 \mathrm{~b}, \Delta 4 \\
\Delta 2 \Delta 5 \mathrm{~b} \\
\Delta 5 \mathrm{c}\end{array}$ \\
\hline $\begin{array}{c}\text { Aeflightin } \\
\text { Exon } 4 \\
\text { Exp. } 2 \\
\end{array}$ & 268 & 58 & $21.6 \%$ & 80 & 0 & 0 & N/A \\
\hline $\begin{array}{c}\text { AeAct-4 B } \\
\text { Exp. } 2\end{array}$ & 268 & 66 & $24.6 \%$ & 80 & 10 & 4 & $\Delta 2, \Delta 10$ \\
\hline
\end{tabular}


S4 Table. Phenotypic and genotypic analysis of AeAct-4 and myo-fem G6 individuals. Raw data obtained following intercross of heterozygous individuals with both phenotypic (flying vs. flightless) and genotypic analysis.

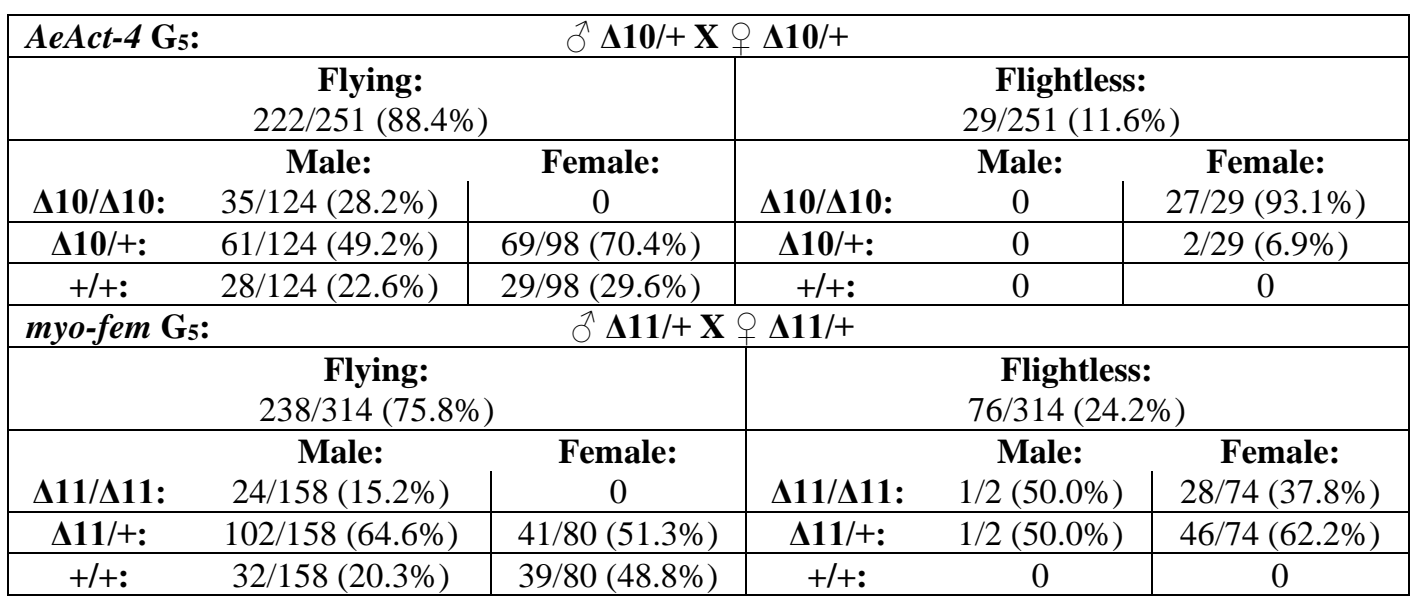


S5 Table. Phenotypic and genotypic analysis of Aeflightin G6 individuals. Raw data obtained following intercross of heterozygous individuals with phenotypic (flying vs. flightless, and white-eyed vs. black-eyed) and genotypic analysis.

\begin{tabular}{|c|c|c|c|c|c|c|c|c|}
\hline \multicolumn{3}{|c|}{ Aeflightin G5: } & \multicolumn{6}{|c|}{$\mathrm{o}^{\lambda}$ Aeflightin $^{\Delta 4 /+} \mathrm{kmo}^{+/-} \mathrm{X}$ ○ Aeflightin ${ }^{\Delta 5 /+} \mathrm{kmo}^{+/-}$} \\
\hline \multicolumn{3}{|c|}{$\begin{array}{c}\text { Flying, white-eyed: } \\
80 / 80(100 \%)\end{array}$} & \multicolumn{3}{|c|}{$\begin{array}{c}\text { Flying, black-eyed: } \\
315 / 463(68.0 \%)\end{array}$} & \multicolumn{3}{|c|}{$\begin{array}{c}\text { Flightless, black-eyed: } \\
148 / 463(32.0 \%)\end{array}$} \\
\hline & Male: & Female: & & Male: & Female: & & Male: & Female: \\
\hline$\Delta 4 / \Delta 5:$ & 0 & 0 & $\Delta 4 / \Delta 5:$ & 0 & 0 & $\Delta 4 / \Delta 5:$ & $48 / 52(92.3 \%)$ & $91 / 96(94.8 \%)$ \\
\hline$\Delta 5 /+:$ & 0 & $1 / 40(2.5 \%)$ & $\Delta 5 /+:$ & $79 / 156(50.6 \%)$ & $69 / 159(43.4 \%)$ & $\Delta 5 /+:$ & 0 & $3 / 96(3.1 \%)$ \\
\hline$\Delta 4 /+:$ & $1 / 40(2.5 \%)$ & 0 & $\Delta 4 /+:$ & $74 / 156(47.4 \%)$ & $90 / 159(56.6 \%)$ & $\Delta 4 /+:$ & $4 / 52(7.7 \%)$ & $2 / 96(2.1 \%)$ \\
\hline$+/+:$ & $39 / 40(97.5 \%)$ & $39 / 40(97.5 \%)$ & $+/+:$ & $3 / 156(1.9 \%)$ & 0 & $+/+:$ & 0 & 0 \\
\hline
\end{tabular}


S6 Table. Mating competition assays between wild type and AeAct-4${ }^{410 / 410}$ or $\boldsymbol{m y o - f e m}{ }^{411 / \Delta 11}$ males. Raw data for each replicate along with the mean of all replicates for the expected and observed progeny genotypes based on male matings for each gene.

\begin{tabular}{|c|c|c|c|c|c|c|c|c|c|c|c|}
\hline Gene & $\begin{array}{c}\# \text { WT } \\
\text { Males (\%) }\end{array}$ & $\begin{array}{c}\text { \# HET } \\
\text { Males } \\
(\%)\end{array}$ & $\begin{array}{c}\text { \# HOM } \\
\text { Males (\%) }\end{array}$ & $\begin{array}{l}\text { \# Total } \\
\text { Males }\end{array}$ & $\begin{array}{c}* \text { Total } \\
\text { Matings }\end{array}$ & $\underset{(\%)}{\# \text { Exp. WT }}$ & $\begin{array}{c}\text { \# Exp. } \\
\text { HET (\%) }\end{array}$ & $\begin{array}{c}\text { \# Obs. WT } \\
(\%)\end{array}$ & $\begin{array}{c}\text { \# Obs. } \\
\text { HET }(\%)\end{array}$ & $\chi^{2}$ & P-value \\
\hline $\begin{array}{c}\text { AeAct-4 } \\
\text { Rep 1 }\end{array}$ & $16(40 \%)$ & $1(3 \%)$ & $23(58 \%)$ & 40 & 26 & $10(38 \%)$ & $16(62 \%)$ & $17(65 \%)$ & $9(35 \%)$ & 7.963 & 0.0048 \\
\hline $\begin{array}{c}\text { AeAct-4 } \\
\text { Rep 2 }\end{array}$ & $23(58 \%)$ & $0(0 \%)$ & $17(43 \%)$ & 40 & 35 & $20(57 \%)$ & $15(43 \%)$ & $30(86 \%)$ & $5(14 \%)$ & 11.667 & 0.0006 \\
\hline $\begin{array}{c}\text { AeAct-4 } \\
\text { Rep } 3\end{array}$ & $16(40 \%)$ & $1(3 \%)$ & $23(58 \%)$ & 40 & 32 & $13(41 \%)$ & $19(59 \%)$ & $22(69 \%)$ & $10(31 \%)$ & 10.494 & 0.0012 \\
\hline $\begin{array}{c}\text { AeAct-4 } \\
\text { Mean }\end{array}$ & & & & & & 14 & 17 & 23 & 8 & & \\
\hline $\begin{array}{c}\text { myo-fem } \\
\text { Rep 1 }\end{array}$ & $21(53 \%)$ & $4(10 \%)$ & $15(38 \%)$ & 40 & 27 & $14(52 \%)$ & $13(48 \%)$ & $21(78 \%)$ & $6(22 \%)$ & 7.269 & 0.0070 \\
\hline $\begin{array}{c}\text { myo-fem } \\
\text { Rep } 2\end{array}$ & $15(38 \%)$ & $0(0 \%)$ & $25(63 \%)$ & 40 & 11 & $4(36 \%)$ & $7(64 \%)$ & $10(91 \%)$ & $1(9 \%)$ & 14.143 & 0.0002 \\
\hline $\begin{array}{c}\text { myo-fem } \\
\text { Rep } 3\end{array}$ & $20(50 \%)$ & $0(0 \%)$ & $20(50 \%)$ & 40 & 31 & $16(50 \%)$ & $16(50 \%)$ & $15(48 \%)$ & $16(52 \%)$ & 0.032 & 0.8575 \\
\hline $\begin{array}{c}\text { myo-fem } \\
\text { Rep } 4\end{array}$ & $20(50 \%)$ & $0(0 \%)$ & $20(50 \%)$ & 40 & 16 & $8(50 \%)$ & $8(50 \%)$ & $10(63 \%)$ & $6(38 \%)$ & 1.000 & 0.3173 \\
\hline $\begin{array}{l}\text { myo-fem } \\
\text { Mean }\end{array}$ & & & & & & 10 & 11 & 14 & 7 & & \\
\hline
\end{tabular}

*Matings are defined as females who blood fed, laid embryos, and hatched. 


\section{Videos}

\section{All videos are included as separate files.}

S1 Video. Flight tests for AeAct-4.

Flightless AeAct-4 individuals on the left, and control individuals on the right. The plastic buckets used to contain the adult mosquitoes were agitated by knocking on either side.

\section{S2 Video. Flight tests for myo-fem.}

Flightless myo-fem individuals on the left, and control individuals on the right. The plastic buckets used to contain the adult mosquitoes were agitated by knocking on either side.

\section{S3 Video. Flight tests for Aeflightin.}

Flightless Aeflightin individuals on the left, and control individuals on the right. The plastic buckets used to contain the adult mosquitoes were agitated by knocking on either side. 


\section{CHAPTER III}

\section{CONCLUSION}

Our results indicate successful CRISPR/Cas9 knockout of AeAct-4, myo-fem, and Aeflightin in Aedes aegypti. The knockout mutants have a completely penetrant, flightless phenotype that is heritable. The AeAct-4 mutants were found to be haplosufficient, with no delay in flight abilities seen in heterozygous females. However, the myo-fem mutants were found to be haploinsufficient, with a delay in gain of flight ability seen as late as 48 hours after emergence in heterozygous females. Further experimentation could be done to analyze this flight delay in individuals, to more carefully determine when and to what extent flightless heterozygous females gain the ability to fly. Information such as this would be optimal for considering use of targeting myo-fem as a sex distortion system for gene drive, due to the increased number of flightless heterozygous females as compared to AeAct-4.

As the Aeflightin knockout flightless phenotype is not female-specific, and produces flightless males, it would be important to be able to accomplish rescue of male flight in these individuals if this gene were to also be considered for use as a target in a gene drive mechanism. We are currently working on characterizing the putative promoter regions of the male-specific AeAct-3 and myo-sex. Provided these promoter regions we have identified prove to have male-specific expression, they could then be used in a transgenic construct to rescue male flight in Aeflightin deficient mosquitoes by directing expression of Aeflightin. Beyond use as a male-specific rescue for flight, 
characterization of these promoters would add to the genetic toolbox we have for $A e$. aegypti and enable other groups to be able to utilize these promoters for various expression-dependent experiments.

We were interested in evaluating mating competitiveness of AeAct-4 and myofem knockout males, as AeAct-4 and myo-fem are expressed at low levels in male pupae, which we hypothesized may contribute to male flight. Our results indicate that myo-fem is dispensable for male mating success, while AeAct-4 is not. However, we did note that these results should be interpreted with caution, due to multiple constrained variables, such as the size of the container used. Further analysis should be performed to better assess male mating competitiveness, with variables such as the size of the container used (including field trials), the quantity of males, and the ratio of males to females being addressed. Female Ae. aegypti have been shown to engage in multiple matings [1], depending on their postmating interval [2] as well as if copulation was interrupted [3]. In addition to assessing male mating competitiveness with these previously mentioned variables being address, evidence of remating should be considered during future experimentation. Flight tones and shifts to match frequencies in Ae. aegypti has been shown as a measure of male reproductive fitness [4-7] and could be heritable [8]. Thus, additional experimentation into these knockout mutants should be considered to evaluate wing beat frequency in males and heterozygous females.

Targeting sex-specific flight genes is likely to be applicable to other species of mosquito including Culex and Anopheles, as these mosquitoes also appear to encode sexspecific flight genes, as mentioned previously. CRISPR/Cas9 has been used successfully 
to knockout the ortholog of AeAct-4, CxAct4, in Culex quinquefasciatus, while HDR has been used to disrupt AeAct-4 in Ae. aegypti with knock-in of a fluorescent protein [9]. This work further rationalizes targeting sex-specific flight genes as a method of population control across different mosquito species. As mentioned previously, males could act as carriers of the gene drive and inherit the transgene, while females are targeted by the gene drive and potentially would not survive to blood feed or reproduce, and thus, reduce the spread of pathogens that cause disease. These sex-specific flight genes are examples of candidate genes that could be targeted via this mechanism. Some work has been done to identify a region within the Ae. aegypti male-determining gene, nix, that could be a target for insertion of components of this gene drive mechanism that would be inherited by males. The nix gene contains two exons (less than 1,000 base pairs of a coding region) and a $>99,000$ base pair intron that is highly repetitive $[10,11]$. We located one unique site in the intron by using BLAST (Basic Local Alignment Search Tool) and analyzing 25 base pair sequences in 2 base pair increments, followed by synthetic gRNA design and embryonic microinjection tests to identify a single region for potential insertion of transgene components.

Even though there are current vector control strategies for Ae. aegypti, alternative methods involving genome editing are being explored to overcome the shortcomings of current strategies. To successfully target this vector, an understanding of the life cycle and the genome are crucial, along with efficient genome editing techniques like CRISPR/Cas9. Transgenic male mosquitoes that carry a construct that does not impact the male fitness, but is lethal to females, is a promising approach to explore for vector 
control. With the ability to edit the genome, in combination with gene drive techniques, there can be progress towards an alternative method to combat the global issue of the spread of disease due to vectors like Ae. aegypti. 


\section{References}

1. Helinski ME, Valerio L, Facchinelli L, Scott TW, Ramsey J, Harrington LC. Evidence of polyandry for Aedes aegypti in semifield enclosures. Am J Trop Med Hyg. 2012;86(4):635-41. Epub 2012/04/12. doi: 10.4269/ajtmh.2012.11-0225. PubMed PMID: 22492148; PubMed Central PMCID: PMCPMC3403777.

2. Degner EC, Harrington LC. Polyandry Depends on Postmating Time Interval in the Dengue Vector Aedes aegypti. Am J Trop Med Hyg. 2016;94(4):780-5. Epub 2016/02/18. doi: 10.4269/ajtmh.15-0893. PubMed PMID: 26880776; PubMed Central PMCID: PMCPMC4824218.

3. Carvalho DO, Chuffi S, Ioshino RS, Marques ICS, Fini R, Costa MK, et al. Mosquito pornoscopy: Observation and interruption of Aedes aegypti copulation to determine female polyandric event and mixed progeny. PLoS One. 2018;13(3):e0193164. Epub 2018/03/09. doi: 10.1371/journal.pone.0193164. PubMed PMID: 29518112; PubMed Central PMCID: PMCPMC5843176.

4. Aldersley A, Cator LJ. Female resistance and harmonic convergence influence male mating success in Aedes aegypti. Sci Rep. 2019;9(1):2145. Epub 2019/02/16. doi: 10.1038/s41598-019-38599-3. PubMed PMID: 30765779; PubMed Central PMCID: PMCPMC6375921.

5. Arthur BJ, Emr KS, Wyttenbach RA, Hoy RR. Mosquito (Aedes aegypti) flight tones: frequency, harmonicity, spherical spreading, and phase relationships. J Acoust Soc Am. 2014;135(2):933-41. Epub 2014/09/23. doi: 10.1121/1.4861233. PubMed PMID: 25234901; PubMed Central PMCID: PMCPMC3985972. 
6. Cator LJ, Arthur BJ, Harrington LC, Hoy RR. Harmonic convergence in the love songs of the dengue vector mosquito. Science. 2009;323(5917):1077-9. Epub 2009/01/10. doi: 10.1126/science.1166541. PubMed PMID: 19131593; PubMed Central PMCID: PMCPMC2847473.

7. Cator LJ, Zanti Z. Size, sounds and sex: interactions between body size and harmonic convergence signals determine mating success in Aedes aegypti. Parasit Vectors. 2016;9(1):622. Epub 2016/12/03. doi: 10.1186/s13071-016-1914-6. PubMed PMID: 27906074; PubMed Central PMCID: PMCPMC5133739.

8. Cator LJ, Harrington LC. The Harmonic Convergence of Fathers Predicts the Mating Success of Sons in Aedes aegypti. Anim Behav. 2011;82(4):627-33. Epub 2011/10/18. doi: 10.1016/j.anbehav.2011.07.013. PubMed PMID: 22003255; PubMed Central PMCID: PMCPMC3190198.

9. Navarro-Paya D, Flis I, Anderson MAE, Hawes P, Li M, Akbari OS, et al. Targeting female flight for genetic control of mosquitoes. PLoS neglected tropical diseases. 2020;14(12):e0008876. Epub 2020/12/04. doi: 10.1371/journal.pntd.0008876. PubMed PMID: 33270627; PubMed Central PMCID: PMCPMC7714197. 10. Matthews BJ, Dudchenko O, Kingan SB, Koren S, Antoshechkin I, Crawford JE, et al. Improved reference genome of Aedes aegypti informs arbovirus vector control. Nature. 2018;563(7732):501-7. Epub 2018/11/16. doi: 10.1038/s41586-018-0692-z. PubMed PMID: 30429615; PubMed Central PMCID: PMCPMC6421076.

11. Turner J, Krishna R, Van't Hof AE, Sutton ER, Matzen K, Darby AC. The sequence of a male-specific genome region containing the sex determination switch in 
Aedes aegypti. Parasit Vectors. 2018;11(1):549. Epub 2018/10/22. doi: 10.1186/s13071018-3090-3. PubMed PMID: 30342535; PubMed Central PMCID: PMCPMC6195999. 